\title{
Outer Hair Cell Power Output and the Cellular Origins of Distortion Products
}

Richard D. Rabbitt

Biomedical Engineering, Otolaryngology, and Neuroscience Program

University of Utah

36 S. Wasatch Drive, SMBB 3100

Salt Lake City, UT 84112

Email: r.rabbitt@utah.edu

Ph: 1801 581-6968

Figures 6

Citations $\quad 91$

Words
265 Abstract
1457 Introduction
1962 Theory
2993 Results
1244 Discussion
1994 Appendix 


\title{
Outer Hair Cell Power Output and the Cellular Origins of Distortion Products
}

\begin{abstract}
Outer hair cells (OHCs) are the cellular motors in the mammalian inner ear responsible for sensitive high-frequency hearing. Motor function requires expression of the protein prestin (SLC26A5) in the OHC lateral membrane, and ultrafast mechano-electrical transduction (MET) in the apical hair bundle. In the present report, electrical power consumption and mechanical power output of isolated OHCs and membrane patches are examined. Results reveal that power output by the prestin-motor complex is tuned to a best frequency and peaks at a frequency much higher than implied by the low-pass characteristic of traditional nonlinear capacitance, and much higher than the whole-cell resistive-capacitive corner frequency. The $\mathrm{RC}$ paradox is resolved by showing the passive membrane capacitance simply stores and releases potential energy without interfering with or diminishing power conversion by the prestin-motor complex. The NLC speed paradox is resolved by showing that the phase of the electrical charge displacement shifts $90^{\circ}$ as the frequency is increased, as required to output power, thereby causing the real part of the NLC to be low pass while attaining motor function through the imaginary part at high frequencies. Power output by the MET-dependent hair bundle motor is also examined, with results indicating the somatic motor provides a bulk of the high-frequency power output. Results further demonstrate how nonlinearity of the prestin-motor complex and nonlinearity of the MET apparatus combine to generate distinct level-dependent cubic and quadratic distortion products near the best frequency (BF) location in the cochlea and basal to BF.
\end{abstract}

Keywords: electromotility, prestin, cochlea, piezoelectricity, electro-mechanics, biological motor, imaginary capacitance 


\section{Introduction}

The cochlea endows mammals with the ability to hear sounds over a remarkably broad frequency bandwidth far exceeding the frequency limit of hearing in other vertebrates. To accomplish this feat, outer hair cells (OHCs) amplify sound-induced mechanical vibrations through somatic electromotility (Brownell, Bader et al. 1985, Ashmore 1987) and active hairbundle movements (Jia and He 2005, Kennedy, Crawford et al. 2005). OHC amplify vibrations in the cochlea near the traveling wave peak (Rhode and Robles 1974, Wang, Steele et al. 2016, Dewey, Applegate et al. 2019), and generate nonlinear vibrational hot spots basal to the best frequency (BF) location (Cooper, Vavakou et al. 2018). The process is nonlinear (O Maoiléidigh and Hudspeth 2013, Fettiplace 2017, Ashmore 2019) and is responsible for generating intracochlear harmonics and distortion products (iDPs) that travel in the reverse direction to generate otoacoustic emissions (OAEs) in the ear canal, and travel in the forward direction to excite apical regions of the cochlea (Frolenkov, Belyantseva et al. 1998, Kemp 1998, LonsburyMartin and Martin 2003, Dong and Olson 2008, Shera and Charaziak 2019, Martin, Stagner et al. 2020). OAEs are commonly measured in the clinic to assess OHC function and are associated with at least two active mechanisms, one driving mechanical amplification and tuning near BF and the second distributed over the region of the cochlea basal to BF (Kemp and Brown 1983, Shera 2004). Distortion product otoacoustic emissions (DPOAEs) evoked by two tones at closely spaced frequencies (e.g. $f_{1}, f_{2}=1.2 f_{1}$ ) have been reported up to $20 \mathrm{kHz}$ in humans (Dreisbach and Siegel 2001), indicating the underlying nonlinear amplification process operates on a cycle-by-cycle basis across the bandwidth of hearing. But precisely how amplification is achieved at high auditory frequencies given biophysical properties of the somatic and hair bundle motors remains a subject of debate (Santos-Sacchi and Tan 2019, Vavakou, Cooper et al. 2019, Rabbitt 2020).

The OHC somatic motor requires expression of the transmembrane protein prestin (Zheng, Shen et al. 2000, Liberman, Gao et al. 2002), which renders OHCs piezoelectric (Curie and Curie 1881) by coupling electrical charge displacement in the motor complex directly to changes in cell length (Iwasa 1993, Gale and Ashmore 1994, Iwasa 1994, Mountain and Hubbard 1994, Tolomeo and Steele 1995, Ludwig, Oliver et al. 2001, Santos-Sacchi and Tan 2018, Rabbitt 2020). Piezoelectric properties are thought to arise from voltage-driven conformational change(s) in prestin oligomers that alter the membrane area occupied by the prestin-motor complex (Ludwig, Oliver et al. 2001, He, Lovas et al. 2014, Ashmore 2019, Lenz, Hartmann et al. 2020). There are conflicting reports attempting to quantify the speed of the somatic motor (the 
$\mathrm{OHC}$ speed paradox), including reports that OHCs operate cycle-by-cycle at high frequencies (Frank, Hemmert et al. 1999, Wang, Steele et al. 2016), reports that prestin-expressing OHCs enable cochlear amplification at frequencies over $120 \mathrm{kHz}$ in bats and whales (Morell, Vogl et al. 2020), reports that voltage-driven OHC electromotility is too slow to operate cycle-by-cycle (Gale and Ashmore 1997, Santos-Sacchi and Tan 2019, Vavakou, Cooper et al. 2019) and reports that low-pass filtering by the $\mathrm{OHC}$ membrane prevents receptor potential driven cycleby-cycle function (Housley and Ashmore 1992, Dallos and Evans 1995). Previous reports based on piezoelectric properties of the $\mathrm{OHC}$ prestin-motor complex support the hypothesis that $\mathrm{OHC}$ operate on a cycle-by-cycle basis at frequencies above their RC corner (Ospeck, Dong et al. 2003, Rabbitt, Clifford et al. 2009, Iwasa 2016), but how OHCs overcome low pass characteristics of NLC and extend power output to ultrasonic frequencies in echolocating species (Racicot, Boessenecker et al. 2019, Morell, Vogl et al. 2020) remains unclear. The present report expands on the suggestion by Rabbitt et al. (Rabbitt, Clifford et al. 2009, Rabbitt 2020) that the "speed paradox" arises from a priori assumptions about how OHC the prestinmotor complex works, and is resolved by considering electro-mechanical power conversion by $\mathrm{OHCs}$.

The OHC somatic motor coexists with a hair bundle motor, potentially a phylogenetic precursor but differing considerably from the somatic motor. Upon excitatory deflection of an $\mathrm{OHC}$ bundle the mechanical stiffness of the bundle decreases and becomes negative in some recordings, corresponding to the bundle doing mechanical work on the environment (Kennedy, Crawford et al. 2005). Negative bundle stiffness measured in OHCs is similar to that measured in bullfrog saccular hair cells (Martin, Mehta et al. 2000), but in OHCs the stiffness change develops over time as the MET current adapts. The stiffness change occurs in less than $1 \mathrm{~ms}$ and is dependent on $\mathrm{Ca}^{2+}$ entering the cell via MET channels (Kennedy, Crawford et al. 2005, Corns, Johnson et al. 2014 ). It has been suggested that the mechanism might be sufficiently fast to support amplification at auditory frequencies, potentially approaching tens of microseconds in some cells (Kennedy, Crawford et al. 2005). Nonlinear stiffness is present under voltage clamp conditions and therefore, unlike the prestin-motor complex, the mechanism is not piezoelectric in nature -- at least on the whole-cell voltage level. Instead, the reduction of $\mathrm{OHC}$ bundle stiffness is related to the channel open probability and the adapting MET current (Kennedy, Crawford et al. 2005). In addition to the MET-dependent motor, OHC bundles deflect in response to voltage commands through intrinsic properties of the bundle itself and interaction 
with the prestin-dependent somatic motor (Jia and He 2005, Kennedy, Evans et al. 2006). This second bundle mechanism has piezoelectric properties.

Cochlear amplification is ultrafast and requires power at frequencies at least two orders of magnitude higher than possible by conventional molecular motors that rely on step-by-step ATP hydrolysis (Lymn and Taylor 1971, Thomas, Imafuku et al. 2001, Cross 2004). The cochlea avoids the limiting speed of hydrolysis by drawing power from the standing endolymphatic potential (EP), an electrochemical battery that is maintained by the metabolically active stria vascularis (Anniko and Wroblewski 1986, Zdebik, Wangemann et al. 2009, Patuzzi 2011, Mercier, Lysaght et al. 2012, Fritzsch, Pan et al. 2015, Koppl, Wilms et al. 2018). The EP varies between species and locations in the cochlea, maintaining a typical voltage near $+90 \mathrm{mV}$ in endolymph (Koppl, Wilms et al. 2018, Li, Liu et al. 2020). The EP drives a standing "silent" current in the cochlea (Zidanic and Brownell 1990), and a sound-induced cycle-by-cycle receptor current dominated by opening and closing of $\mathrm{OHC}$ mechano-electrical transduction (MET) channels (Dallos and Cheatham 1976). The electrical power entering a single OHC via MET channels for a $1 \mathrm{mV}$ receptor potential modulation is estimated here to be tens of $f W \mathrm{mV}^{2}$, which is adequate to account for the cycle-by-cycle power required to support cochlear amplification (Dong and Olson, Wang, Steele et al. 2016). It is therefore reasonable to hypothesize that $\mathrm{OHCs}$ are powered by the EP, drawing from electrical and chemical potential energies. MET channel permeability to $\mathrm{Ca}^{2+}$ is about 5 times higher than $\mathrm{Na}^{+}$and $\mathrm{K}^{+}$(Beurg, Evans et al. 2006), but given the high endolymphatic $\left[K^{+}\right]$( 154 mM (Bosher and Warren 1971)) relative to $\left[\mathrm{Ca}^{2+}\right](\sim 20 \mu \mathrm{M}$ to $30 \mu \mathrm{M}$, (Bosher and Warren 1978)) the MET electrical power entering OHCs is carried almost entirely by $K^{+}$. It is this $K^{+}$current that powers the somatic $\mathrm{OHC}$ motor. The precise power source for the bundle motor is not yet completely understood. But, it has been shown that the motor has a component that functions under voltage clamp conditions, and that MET $\mathrm{Ca}^{2+}$ influx is required (Kennedy, Crawford et al. 2005, Corns, Johnson et al. 2014), suggesting the power source is likely to draw from the $\mathrm{Ca}^{2+}$ chemical potential. Since $K^{+}$is the dominant ion both intra- and extra-cellular, space-charge neutrality implies $K^{+}$entering the cell would have almost no impact on the local $\left[K^{+}\right]$or chemical potential in stereocilia. In contrast, a continuous $7 p A \mathrm{Ca}^{2+}$ current entering the cell is predicted to increase $\left[\mathrm{Ca}^{2+}\right]$ in the stereocilia from $\sim 200 \mathrm{nM}$ to $10 \mu \mathrm{M}$, with a large percentage of $\mathrm{Ca}^{2+}$ ions extruded by ATPaces in the stereocilia membrane (Beurg, Nam et al. 2008, Beurg, Nam et al. 2010) and the remaining MET $\mathrm{Ca}^{2+}$ ions regulated by mitochondria in the apical cell body (Beurg, Fettiplace et al. 2009, Chen, Mahendrasingam et al. 2012, Fettiplace and Nam 2019). Although 
$\mathrm{Ca}^{2+}$ homeostasis in the stereocilia appears to be relatively slow (Fettiplace and Nam 2019), cycle-by-cycle $\left[\mathrm{Ca}^{2+}\right]$ modulation would be expected to superimpose on top of the rectified [ $\left.\mathrm{Ca}^{2+}\right]$ increase, providing a hypothetical power source driving cycle-by-cycle bundle amplification via the modulating chemical potential.

In the present report, simple methods are presented to estimate $\mathrm{OHC}$ power consumption and output from experimental data, and a "toy" model is used to further elucidate how OHCs output power at high auditory frequencies. Results demonstrate why OHCs output peak power at frequencies well above their intrinsic membrane RC time constant, explain why maximum power is delivered to the cochlea near BF, and why the intrinsic properties of OHCs generate iDPs near the traveling wave peak as well as basal to the peak

\section{Theory}

The present report is focused on power conversion and mechanical power output by OHCs, analyzed below from electrical and mechanical perspectives.

Electrical Power Consumed. The following power analysis is predicated on the hypothesis that the $\mathrm{OHC}$ motors are powered entirely by EP driven ionic current entering the cell, which is partially converted into mechanical power output through voltage-driven electrical charge displacement $q^{p}$ in the soma by the prestin-motor complex and bundle, and through the action of $\mathrm{Ca}^{2+}$ in the MET-dependent hair bundle motor. For the voltage-dependent component, electro-mechanical power conversion can be estimated by treating the $\mathrm{OHC}$ as a single electrical compartment, where the voltage and current are related by Kirchhoff's law:

$$
c^{l} \frac{d v}{d t}+\frac{d q^{p}}{d t}+i_{i}=i
$$

The voltage is $v$, the input current is $i$ and the total ionic current is $i_{i}=\sum_{n=1}^{N} g_{n}\left(v-E_{n}\right.$ ) (see Discussion for role extracellular voltage). The electrical displacement current in the passive membrane is $c^{l} \frac{d v}{d t}$, which acts in parallel with voltage driven electrical displacement currents driving $\mathrm{OHC}$ motor function, $\frac{d q^{p}}{d t}$. Charge displacement in the prestin-motor complex is summed with charge displacement in the voltage-driven component of hair bundle deflection as convolutions: $\frac{d q^{p}}{d t}=c^{s} \otimes \frac{d x^{s}}{d t}+c^{b} \otimes \frac{d x^{b}}{d t}$, where $\quad x^{s}$ is the somatic displacement arising from 
strain $s^{p}$ in the prestin-motor complex and $x^{b}$ is bundle displacement. The parameters $c^{s}$ and $c^{b}$ are capacitance susceptibilities driven by somatic strain and bundle displacement respectively. Electrical power is estimated in the frequency domain for small perturbations about a reference state $\left(v_{o}, i_{o}, x_{o}^{s}, x_{o}^{b}\right)$. Linearizing and taking the Fourier transform of Eq. 1 gives:

$$
C^{L} j \omega V+C^{S} j \omega X^{S}+C^{B} j \omega X^{B}+I_{i}=I
$$

where upper case denotes the frequency domain, superscript $S$ denotes the soma, superscript $B$ denotes the bundle, $\omega$ is frequency $\left(\right.$ rad-s ${ }^{-1}$ ) and $j=\sqrt{-1}$. The coefficient $C^{S}=\frac{\partial Q}{\partial X^{s}}$ determines the electrical current driving the prestin-motor complex in the soma, and the coefficient $C^{B}=\frac{\partial Q}{\partial X^{B}}$ determines the electrical current driving voltage-dependent bundle movements. $I_{i}$ describes the linearized ionic currents in the frequency domain and consists of capacitive, conductive, and inductive components (e.g. (Sirovich and Knight 1977)). I is the input current via the MET channels $I=I\left(X^{B}, V\right)$, voltage clamp $I=I(V)$ or current clamp.

Electrical power is determined by multiplying Eq. 2 by the complex conjugate of voltage $\left(V^{*}\right)$ and taking half of the real part. The left-hand side gives the electrical power input $P_{E}$ :

$$
P_{E}=\frac{1}{2} \operatorname{Re}\left(I V^{*}\right)
$$

which is the receptor power available from cycle-by-cycle modulation of the MET receptor current and the receptor voltage. The right-hand side gives the electrical power lost to ionchannels:

$$
P_{I}=\frac{1}{2} \operatorname{Re}\left(I_{i} V^{*}\right)
$$

the electrical power consumed by the prestin-motor complex:

$$
P_{P}=\frac{1}{2} \operatorname{Re}\left(j \omega C^{S} X^{S} V^{*}\right)
$$

and the electrical power consumed by voltage-dependent bundle movements: 


$$
P_{P B}=\frac{1}{2} \operatorname{Re}\left(j \omega C^{B} X^{B} V^{*}\right) .
$$

A small fraction of the electrical power consumed by the motors is dissipated as heat while the remainder is delivered to the mechanical load with electro-mechanical efficiency $\epsilon$. For small perturbations about the reference state, the coefficients $C^{S}$ and $C^{B}$ are constants. Frequency and load dependence arise from the somatic $X^{S}$ and bundle displacements $X^{B}$. The coefficient $C^{S}$ and $C^{B}$ can be determined experimentally in the frequency domain after blocking ion channels. The direct approach is to measure $V, I, X^{S}$ and $X^{B}$ and apply Eq. 2 to estimate $C^{S}$ and $C^{B}$. Alternatively, assuming the efficiency is high, Eq. 5 and/or 6 can be combined with measurements of mechanical power output to estimate $C^{S}$ and $C^{B}$.

The classical form for $\mathrm{OHC}$ nonlinear capacitance measured under voltage clamp conditions is found by letting the strain be a function of voltage and force: $X^{S}=X^{S}\left(V, F^{S}\right)$. Expanding strain in a Taylor series in voltage and force gives the total capacitive current $j \omega C^{S} X^{P S}=j \omega\left(C^{V} V+\right.$ $C^{F S} F^{S}$ ), where $C^{V}=C^{S} \frac{\partial X^{S}}{\partial V}$ and $C^{F S}=C^{S} \frac{\partial X^{S}}{\partial F^{S}}$. After blocking ion channels, $C^{V}$ can be measured in voltage clamp under constant force, and $C^{F S}$ can be measured in force clamp under constant voltage. Both $C^{V}$ and $C^{F S}$ depend on the mechanical strain in the prestin-motor complex and how the cell is loaded (Rabbitt 2020). Under ideal voltage clamp, a command voltage $V$ causes the cell to displace against the load imposed by the cell itself and the environment (stiffness, viscosity, mass). When working against a load, the force is a frequency-dependent function of voltage (e.g. $F^{S}=T^{V F} V$, where $T^{V F}$ is a transfer function relating force to voltage). Writing the total capacitive current for a loaded cell as $j \omega C^{N} V$ (where $C^{N}=C^{V}+T^{V F} C^{F S}$ ), the power consumed by the prestin-motor complex is given by the simple expression (Rabbitt 2020):

$$
P_{P}=\frac{-\omega}{2} \operatorname{Im}\left(C^{N}\right) V^{2}
$$

where $C^{N}$ is the traditional OHC NLC recorded under voltage clamp. At low frequencies the load is dominated by stiffness, causing the force to be in phase with the voltage and $C^{N}$ to be real-valued. When $C^{N}$ is real-valued there is no power conversion and no motor function. As frequency is increased, viscosity begins to dominate, shifting the phase of the force by $-90^{\circ}$ and introducing a negative imaginary-valued NLC component, $\operatorname{Im}\left(C^{N}\right)$. Power output is maximized 
at a frequency just above the peak negative $\operatorname{Im}\left(C^{N}\right)$. As frequency is further increased mass dominates, shifting the phase of the force by $180^{\circ}$ and eliminating $\operatorname{Im}\left(C^{N}\right)$. For the prestinmotor complex to work as an electro-mechanical motor with $P_{P}>0$ requires $C^{N}$ to be imaginaryvalued and negative. Indeed, $\operatorname{Im}\left(C^{N}\right)$ emerges at high frequencies in OHCs and membrane patches as $\operatorname{Re}\left(C^{N}\right) \rightarrow 0$ and viscosity begins to consume power (Rabbitt 2020, Santos-Sacchi, Navaratnam et al. 2020).

Mechanical Power Output by Prestin- and MET-dependent motors. In the frequency domain, mechanical power output by the prestin-motor complex is:

$$
P_{P M}=\frac{1}{2} \operatorname{Re}\left(F^{S}\left(j \omega X^{S}\right)^{*}\right),
$$

where $X^{S}$ is the axial cell displacement and $F^{S}$ is the axial somatic force. For a 1D homogeneous piezoelectric model of the prestin-motor complex the force is related to the displacement and the voltage by $F^{S}=\frac{1}{\kappa \ell} X^{S}+\frac{\delta}{\kappa} V$, where $\kappa$ is the compliance, $\ell$ is the cell length, $\delta$ is the piezoelectric strain coefficient and $X^{S}=S^{S} \ell$ is the whole cell axial displacement arising from strain $S^{S}$ in the piezoelectric prestin-motor complex. Substituting into Eq. 8 gives the piezoelectric prediction: for mechanical power output:

$$
P_{P M} \approx \frac{-\delta \omega}{2 \kappa} \operatorname{Im}\left(X^{S} V^{*}\right)
$$

where the stiffness term is conservative and results in zero power. Eq. 9 was derived from mechanical power and is equivalent to Eq. 5 derived from electrical power. Comparing results identifies $C^{S}=\frac{\delta}{\kappa}$ as the somatic piezoelectric force coefficient. An analogous result for the bundle identifies $C^{B}$ as the bundle piezoelectric force coefficient. Interestingly, the mechanical power output is zero if the voltage is in phase with the displacement, and maximized if the voltage is in phase with velocity. In low frequency voltage clamp recordings from $\mathrm{OHCs}$ in the dish, voltage is indeed in phase with displacement and power output is zero. Hence, low frequency electromotility is only indirectly related to $\mathrm{OHC}$ function as a motor. Significant power output only occurs at high frequencies as viscosity of the load compels the cell displacement to shift $\sim 90^{\circ}$ relative to the voltage. 
The hair-bundle motor is assumed to be the addition of two components, one powered by the $\mathrm{Ca}^{2+}$ component of the MET current, $I_{\mathrm{Ca}}$, and the other powered electrically. A modified gating spring model (Howard and Hudspeth 1988, Kennedy, Evans et al. 2006) relates the bundle displacement, force and voltage by:

$$
f^{b}=k^{b}\left(x^{b}-a\left(P\left(x^{g}\right)-P_{o}\right)\right)+c^{b}\left(v-v_{o}\right)
$$

where $k^{b}$ is the passive bundle stiffness, $a$ is a constant and $P\left(x^{g}\right)$ is the nonlinear channel open probability accounting for fast adaptation (see Appendix). The term $c^{b}\left(v-v_{o}\right)$ has been added to account for voltage evoked bundle force, recognizing its relationship to somatic electromotility (Jia and $\mathrm{He}$ 2005, Kennedy, Evans et al. 2006). For small displacements $F^{B} \approx k^{B}\left(X^{B}-a s X^{G}\right)+C^{B} V$, where $s$ is the slope of the open probability and $X^{G}$ is the channel gating parameter, approximately proportional to bundle velocity (O Maoiléidigh and Jülicher 2010, Szalai, Tsaneva-Atanasova et al. 2011) and putatively driven by $\mathrm{Ca}^{2+}$. Multiplying the linearized version of Eq. 10 by the complex conjugate of bundle velocity and dividing the real part by 2 gives the mechanical power output of the bundle:

$$
P_{B M} \approx \frac{a s K^{B} \omega}{2} \operatorname{Im}\left(X^{G} X^{B^{*}}\right)+\frac{-C^{B} \omega}{2} \operatorname{Im}\left(V X^{B^{*}}\right)
$$

Similar to the somatic motor, the elastic term contributes no power. The first term arises from MET-adaptation dependent motility and the second term arises from voltage driven motility. The first term is zero in this model if channel gating is in phase with bundle displacement, and maximized if channel gating is in phase with bundle velocity. Hence, in the absence of voltage sensitivity, gating adaptation appears to be required for power output if the force has the gating spring form of Eq. 10.

Mechanical Power Dissipated by the Extrinsic Load. Electro-chemical power consumed by $\mathrm{OHC}$ molecular motors is partially dissipated by heat and partially transmitted to the extrinsic mechanical load -- a load that varies systematically in the cochlea along the tonotopic map. Insight can be gained into $\mathrm{OHC}$ power output by my treating the cochlear load as a simple spring-mass-damper (O Maoiléidigh and Jülicher 2010). Applying Newton's 2nd law to the mass (see Fig. 1) provides: $D^{L} X^{L}=F-F^{S}-F^{B} / r=F^{T}$, where the frequency domain operator $D^{L}$ is 


$$
D^{L}=K^{L}\left(1-\left(\frac{\omega}{\omega_{0}}\right)^{2}+\zeta^{L}\left(\frac{j \omega}{\omega_{0}}\right)^{n}\right)
$$

$X^{L}$ is displacement of the load and the total force is $F^{T} . F$ is the externally applied force, $F^{S}$ is the intrinsic somatic force generated by the prestin-motor complex, $F^{B}$ is the force generated by the MET-dependent bundle motor and $r$ is a lever ratio relating the transverse bundle force to the axial OHC force. Stiffness of the load is $K^{L}$, the natural frequency is $\omega_{0}$ and the nondimensional viscous drag coefficient is $\zeta^{L}$. Eq. 12 uses a fractional derivative $n$ to model the viscous load, which gives rise to a power-law " $n$ " frequency dependence of $N L C$ similar to that observed experimentally in OHCs $(0.7<n<0.9$ (Rabbitt 2020)). For an isolated cell in the dish, $D^{L}$ describes intrinsic properties of the cell itself and the media, and in the cochlea $D^{L}$ describes the addition of the intrinsic properties plus the cochlear load with parameters adjusted accordingly. Multiplying Eq. 12 by velocity and averaging over time provides the power consumed by the viscous load in the frequency domain:

$$
P_{M}=\frac{1}{2} \operatorname{Re}\left(F^{T}\left(j \omega X^{L}\right)^{*}\right)=\frac{c \omega^{1+n}}{2} \sin \left(\frac{n \pi}{2}\right) X^{L^{2}}
$$

where the damping parameter $c=\frac{K^{L} \zeta^{L}}{\omega_{0}^{n}}$. For $n=1$, Eq. 13 reduces to the well-known expression for power consumption by a viscous damper: $P_{M}=\frac{c \omega^{2}}{2} X^{2}$. As expected, mass and stiffness do not appear in Eq. 13.

Total mechanical power output can easily be estimated from Eq. 13 based on whole-cell displacement in the frequency domain providing the viscous dissipation parameters $c$ and $n$ are known. As an alternative to Eq. 13, experimentally measured motion can be combined with 3D computational mechanics to estimate the power delivered to the extrinsic load (Tolomeo and Steele 1998, Wang, Steele et al. 2016).

Nonlinearity and Distortion Products. All equations in the above power analysis were linearized for small sinusoidal perturbations about a reference operating point (e.g.: $x=x_{o}+$ $\left.\frac{1}{2}\left(X e^{j \omega t}+X^{*} e^{-j \omega t}\right), v=v_{o}+\frac{1}{2}\left(V e^{j \omega t}+V^{*} e^{-j \omega t}\right), f=f_{o}+\frac{1}{2}\left(F e^{j \omega t}+F^{*} e^{-j \omega t}\right) \ldots\right)$. The influence of nonlinearity appears only through coefficients, which are saturating functions of the 
reference cell state. For example, Eq. 2 contains two key electro-mechanical coefficients: $C^{S}$ and $C^{B}$ that describe electro-mechanics of the soma and bundle respectively. Both are nonlinear functions of cell state that change with voltage, strain, force and bundle deflection -saturating for deviations outside the functional operating range (see Appendix). These "piezoelectric" coefficients give rise to other nonlinear parameters including NLC. In the METdependent bundle motor, nonlinearity enters through the saturating and adapting open probability. Linearization is a useful tool for power analysis, but the approach is unable to capture inherently nonlinear behaviors such as self-excited vibrations, stability transitions and harmonic distortion (Martin, Bozovic et al. 2003, Szalai, Tsaneva-Atanasova et al. 2011, O Maoiléidigh and Hudspeth 2013). Understanding how the MET and somatic motors lead to OAEs requires a nonlinear analysis.

To examine the role of OHC somatic and bundle motors on the generation of mechanical iDPs, a relatively simple model of a single $\mathrm{OHC}$ under load was applied (see Appendix and Fig. 1). Nonlinearities introduced by the somatic prestin-motor complex and the MET-dependent hair bundle motor were included. Equations were integrated numerically in the time domain in response to sinusoidal forces at closely spaced frequencies $\left(f_{1}, f_{2}=1.2 f_{1}\right)$ to examine relative contributions of the bundle and somatic nonlinearities on iDPs.

\section{$\underline{\text { Results }}$}

Mechanical Power Output Delivered to the Dissipative Load, $\boldsymbol{P}_{M}$. To determine frequency dependence of $\mathrm{OHC}$ motor function in isolated cells, mechanical power output was determined from high-frequency displacement data reported by Frank et al. (1999) (Frank, Hemmert et al. 1999). The procedure requires first estimating the viscous dissipation coefficient " $c$ " and powerlaw exponent " $n$ ", and then applying Eq. 13 to estimate the power output. The parameters were estimated from the frequency dependence of whole-cell displacement driven by extracellular voltage in the $\mu$-chamber (large pipette) configuration. Fig. 2A illustrates the $\mu$-chamber recording set up and 2B-C show the displacement (magnitude and phase) recorded in response to sinusoidal voltage commands for $\mathrm{OHCs}$ of two different lengths extending outside of the chamber. Although the precise holding potential and transmembrane voltage modulation were unknown in these experiments, it was still possible to use the data to determine the mechanical power output by OHCs. Solid curves curve fits to a spring-mass-damper under sinusoidal force (Eq. 12) were used to estimate " $c$ " and " $n$ ". The mechanical power output was then determined by Eq. 13, with the result shown in Fig. 2D. The isometric force generated in the $\mu$-chamber 
configuration ( $0.03 \mathrm{nN}-\mathrm{mV}^{-1}$ (Frank, Hemmert et al. 1999)) is smaller than in whole-cell voltage clamp ( 0.10 $\mathrm{nN}^{-} \mathrm{mV}^{-1}$ (Iwasa and Adachi 1997)), suggesting the power output would be higher under ideal voltage clamp compared to the extracellular voltage commands in the $\mu$-chamber. Nevertheless, the $\mu$-chamber data clearly show OHCs are capable of outputting substantial power at ultrasonic frequencies, peaking at $32 \mathrm{kHz}$ for the larger cell and $74 \mathrm{kHz}$ for the smaller cell (Fig. 2D). OHC power output in the Frank et al. experiments was maximum when the displacement of the cell lagged the stimulus voltage by $\sim 90^{\circ}$. We know from simple mechanical systems (e.g. Eq. 12) that power consumption by the viscous load is maximum when velocity is in phase with the force. This implies the speed of force generation in response to voltage was nearly instantaneous in the Frank et al. experiments, consistent with the isometric force Bode plots in the same report (Fig. 4 in (Frank, Hemmert et al. 1999)). Results demonstrate the frequency limit of $\mathrm{OHC}$ power output is not the speed of force generation in the prestin-motor complex, but instead is limited by the ability of the force to displace the load. The frequency of maximum power output is aligned with the natural frequency of the total load $\omega_{o}$ (near BF in the cochlea), and the speed is ultimately limited by the effective mass of the load.

Electrical Power Converted by the Prestin-Motor Complex $P_{P}$. To determine the speed of the prestin-motor complex, frequency-dependent electrical power consumption was estimated from macro-patch NLC data reported by Gale \& Ashmore (1997) (Gale and Ashmore 1997). The experimental approach measured $\operatorname{Re}\left(C^{N}\right)$, with data reproduced in Fig. 3A (blue symbols). The data clearly show $\operatorname{Re}\left(C^{N}\right)$ declining with frequency. $\operatorname{Re}\left(C^{N}\right)$ has a low-pass characteristic beginning to roll off as near $2 \mathrm{kHz}$ and showing a power-law frequency dependence $(n=0.7$, solid black curve from theoretical curve fit using (Rabbitt 2020)). But, as shown above, the real component of NLC is not related to power output and therefore has little to do with function of the prestin-motor complex as a motor. To estimate power output in the Gale \& Ashmore experiments, $\operatorname{Re}\left(C^{N}\right)$ was used to determine the corresponding $\operatorname{Im}\left(C^{N}\right)$ component (3B, red), which was accomplished by assuming the macro-patch was working against a visco-elastic load described by Eq. 12. Curve fitting the frequency dependence of $\operatorname{Re}\left(C^{N}\right)$ (3A, black) provided the frequency dependence of $\operatorname{Im}\left(C^{N}\right)(3 \mathrm{~B}$, red). Eq. 7 was then used to estimate the frequency dependent power consumed by the prestin-motor complex in the Gale \& Ashmore macro-patch experiments $(3 C)$. The power output was not limited by the low-pass character of real NLC recorded in the experiments, but instead was tuned to output maximum power at a much higher frequency, estimated here as $37 \mathrm{kHz}$ (3C, vertical dashed line). This defines the speed of power consumption by the prestin-motor complex when driving the mechanical load present in 
the macro-patch configuration. As expected from first principles (Theory), maximum power output occurs at a frequency where $\operatorname{Re}\left(C^{N}\right) \rightarrow 0$ and just above the frequency where $\operatorname{Im}\left(C^{N}\right)$ reaches its peak negative value. By conservation of energy, the power consumed by the motor (3C) must be delivered to intrinsic dissipation of the membrane complex itself and to vibration of the fluid media. Almost identical frequency dependence was reported using macro-patch recordings from guinea pig OHCs by Santos-Sacchi \& Tan (2020) (Santos-Sacchi and Tan 2020), but with higher absolute NLC values presumably arising from differences in patch size. Predicted voltage and frequency dependence of the real and imaginary components of macropatch capacitance are show in Fig. 3D based on a simple 1D PZT model of the fluid-loaded membrane patch (Rabbitt 2020).

Power analysis of data from isolated OHCs (Fig. 2) and macro-patches (Fig. 3) clearly demonstrates that maximum $\mathrm{OHC}$ power conversion by the prestin-motor complex occurs at frequencies much higher than would be expected based on traditional measures of NLC, RC corner frequency, or cell displacement. Based on Eq. 13, maximum power output occurs at a best frequency dictated by mechanics of the load. In voltage clamp experiments in isolated cells or membrane patches, the load consists of elasticity, mass, and viscosity of the cell and membrane itself plus the fluid media. Force generated by the OHC works against stiffness of the cell/patch at low frequencies and against inertia of the cell and fluid at high frequencies, thwarting power delivery to the load at both low and high frequencies. Efficient power delivery occurs only at the natural frequency $\omega_{o}$ of the total load where the elastic and inertial forces balance and the viscous force dominates (Eqs. 11,13). For the prestin-motor complex, this occurs when the voltage is in phase with velocity (Eqs. 5,6), and when the electrical displacement current is in phase with voltage (i.e., the NLC must be imaginary valued). The same electrical and mechanical principles apply to the bundle motors (Eq. 11), with the caveat of the chemical potential. To understand how OHCs power the cochlear amplifier it is essential to consider how they work in the context of the cochlear load (O Maoiléidigh and Hudspeth 2013).

Role of the Cochlear Load in OHC Power Conversion. To examine OHC power delivery to the viscous cochlear load, a "toy" 1D model was constructed as illustrated in Fig. 1 (see Appendix for equations). Example results are shown in Fig. 4 for a $25 \mu \mathrm{m}$ long OHC subject to a simulated cochlear load with best frequency (BF) of $\omega_{o}=6 \mathrm{kHz}$. The passive linear capacitance of the $\mathrm{OHC}$ was $22 \mathrm{pF}$ and the peak NLC at $100 \mathrm{~Hz}$ was $24 \mathrm{pF}$. To illustrate the 
effect of the $\mathrm{RC}$ corner frequency, results are shown for low and high membrane resistances $(\mathrm{R})$ associated with passive membrane corner frequencies of $5.5 \mathrm{kHz}$ (thin curves) and $200 \mathrm{~Hz}$ (thick curves) respectively. Remaining model parameters are provided in Table 1. The magnitude of cycle-by-cycle displacement (d), current (i), voltage (v), force (f) and power (p) are shown relative to the stimuli (VC re: $\mathrm{mV}, \mathrm{CC}$ re: $\mathrm{pA}, \mathrm{FC}$ re: $\mathrm{nN}$ ). Phase relative to each stimulus is also shown for the high resistance condition $(\mathrm{ph})$. Columns show results for voltage clamp ( $\mathrm{A}$ : left VC), current clamp (B: center CC) and force clamp (C: right FC). VC and CC simulations assume MET channels are blocked and ideal voltage or current commands are applied to the mechanically loaded cell via a patch electrode. Hence, results for VC and CC only address function of the prestin-motor complex working against simulated cochlear load. FC simulations show responses to a sinusoidal force applied to the external load (see Fig. 1) and include both the bundle and somatic motors, which comes closer to mimicking physiological stimulation in the cochlea.

Under ideal VC (Fig. 4A, left), OHC displacement (4A, d) shows a resonant behavior dictated by the mechanical load, almost identical to a simple spring-mass-damper (Eq. 12) driven by sinusoidal force. The displacement and force in the prestin-motor complex $(4 \mathrm{~A}, \mathrm{f})$ are set by the voltage and are unaltered by changes in the RC corner frequency. Mechanics of the load (Eq. 12) causes the displacement causes the phase to shift by $180^{\circ}(4 \mathrm{~A}$, ph, black) as the frequency transits the best frequency $(B F)$ and the load shifts from stiffness dominated, to viscous drag dominated and ultimately to mass dominated. The phase of the force in the prestin-motor complex shifts by $90^{\circ}$ at BF as the force aligns with viscous drag. The maximum mechanical power output occurs at the natural frequency of the load $\omega_{o}(4 A, p, B F)$. At BF, the mechanical power output is nearly equal to the electrical power consumed (4A, p, green) providing the membrane resistance is sufficiently high. Lowering the membrane resistance $R$ and increasing the $\mathrm{RC}$ corner frequency has no effect on the power output under voltage clamp, but lowering $\mathrm{R}$ does introduce a frequency-independent power loss through the membrane conductance $(4 \mathrm{~A}, \mathrm{p}$, thin vs thick green curves). The impedance of the $\mathrm{OHC}$ motor is matched closely to the load only at BF, where the ratio of mechanical power output (4p, black) to electrical power input (4p, green) is maximized. Stiffness of the load prevents power output at low frequencies and mass of the load prevents power output at high frequencies.

Under ideal CC (Fig. 4B, center), the membrane time constant causes the voltage to decline above the cell $\mathrm{RC}$ corner resulting is a low-pass filtered voltage $(4 \mathrm{~B}, \mathrm{v}$, red dashed, low and 
high $R$ cases shown). Concomitant low-pass filtering is introduced into both the displacement $(4 B, d)$ and force $(4 B, f)$ relative to $V C$ conditions $(4 A)$. Changing membrane $R$ has a significant effect on electrical power consumption under CC conditions, but only very modest effects on mechanical power output near BF. Mechanical power output is more sharply tuned for the low $R$ case $(4 B, p$, thin black) vs the high $R$ case $(4 B, p$, thick black), but peak power output is almost unchanged. The power efficiency at BF is nearly identical for VC vs. CC conditions, clearly demonstrating that the $\mathrm{RC}$ corner frequency has very little to do with power output at best frequency. The only relevance of the passive $\mathrm{RC}$ in this context is how much electrical power input is lost to electrical dissipation by heat (in VC and CC).

To examine how OHCs might respond to sinusoidal forces in the cochlea, the exact same model used for VC and CC simulations (4A, 4B) was excited by a sinusoidal force applied to the external load (Fig. 1A, f). The force drives displacement of the load, which results in forces on the prestin-motor complex and the bundle. The two forces drive bundle displacement, gate the MET current, and drive charge displacement in the prestin-motor complex via the piezoelectric effect. Near BF, forces generated by the somatic motor and the bundle motor add to the applied force to enhance vibration of the load. Prior to presenting results, it's important to note that this positive feedback loop injects power into mechanical vibrations, and as the gain is increased instability arises and the system enters a mode of nonlinear self-excited vibration. This transition corresponds to a Hopf bifurcation (O Maoiléidigh and Hudspeth 2013). Parameters used in the present analysis are on the stable side of the bifurcation where vibrations require external forcing and decay to zero in the absence of force inputs.

Responses of the linearized model to sinusoidal force clamp (FC) are shown in right column of Fig. 4C, with model parameters identical to VC (left) and CC (center) columns. Unlike VC and CC, FC results exhibit resonant behavior in displacement (d), voltage (v), current (i), force (f) and power $(p)$. Power output $(4 \mathrm{C}, \mathrm{p}$, black) is similar to $\mathrm{CC}$, but power consumption (4C, $\mathrm{p}$, green) is greatly reduced across the full frequency bandwidth. Results predict there is almost no electrical loss above BF. It should be noted that present simulations do not include mechano-sensitive or voltage-gated ion channels in the basolateral membrane, which could potentially further improve tuning and reduce electrical losses at low frequencies (Ospeck, Dong et al. 2006, Perez-Flores, Lee et al. 2020) (reduce the green hatched area). The power output by the bundle motor (adaptation-dependent motor plus the voltage-dependent motor) (4C, $\mathrm{p}$, thick red curve) is predicted to be an order of magnitude smaller than the prestin-motor 
complex. No speed limits were imposed on the bundle motors in the simulations, and parameters were based on $\mathrm{OHC}$ data from Kennedy et al. (2005) (Kennedy, Crawford et al. 2005) and Jia \& He (2005) (Jia and He 2005). Results suggest the prestin-based motor is likely responsible for almost all of the power output at BF in a $24 \mu \mathrm{m}$ long OHC. Under FC conditions the cell is excited by displacement of the hair bundle, which is controlled to a major extent by the extrinsic load acting on the cell. As a result there was very little change in frequency dependence of voltage or current in response to changing $R$, with results after lowering the membrane resistance $R$ and increasing the membrane corner frequency to $5.5 \mathrm{kHz}$ shown as thin curves in $4 \mathrm{C}$. Lowering the membrane resistance reduced the mechanical power output $(4 \mathrm{C}, \mathrm{p}$, thin vs. thick black curves) which is likely relevant to action of efferent synaptic inputs (Rabbitt, Clifford et al. 2009), but had little effect on the electrical power consumed at BF.

Origin of Intracochlear Distortion Products. To examine how mechanical intracochlear distortion products (iDPs) are related to nonlinearities in the MET complex and prestin-motor complex, the model in Fig. 1 was solved numerically in the time domain under ideal VC and FC conditions and analyzed to associate iDP signatures with their cellular source. Mechanical vibrations of a single $\mathrm{OHC}$ subject to a spring-mass-damper mechanical load mimicking the BF location in the cochlea are shown in Fig. 5 in response to a primary at $f_{1}=6 \mathrm{kHz}$ and a secondary at $f_{2}=7.2 \mathrm{kHz}$. Mechanical vibration is shown as a function of frequency for 3 different levels of the primary stimulus: in VC from 0 to $10 \mathrm{mV}$ and in FC from 0 to $10 \mathrm{nN}$.

Mechanical iDPs generated by OHCs under VC commands bypass the MET apparatus and drive the prestin-motor complex directly. For a pure sinusoidal $10 \mathrm{mV}, 7.2 \mathrm{kHz} \mathrm{VC}$ command, just above BF and about $V^{p k}$, mechanical iDPs are predicted at odd harmonics, shown as peaks in Fig. 5A (right: e.g. $3 f_{2}, 5 f_{2}$ ). Mechanical power is output by each peak and can be estimated from the magnitude of the peak (Fig. 4 and Eq. 13). The harmonics arise from voltage dependence of the nonlinear charge displacement in the $\mathrm{OHC}$ lateral wall membrane $\left(c^{s}\right)$, which is dominated by a cubic nonlinearity for small perturbations about $V^{p k}$. The spectrum is augmented with even harmonics if the center voltage differs from $V^{p k}$, and/or if the stimulus strength is further increased. The model used here did not exhibit significant subharmonics. Addition of another stimulus at frequency $f_{1}=6 \mathrm{kHz}$ matching BF of the load evokes vibration not only at the stimulus frequencies but also at cubic distortion product frequencies: $2 f_{1}-f_{2}, 2 f_{2}-f_{1}, 3\left(f_{2}-f_{1}\right) \ldots$. Additional iDPs emerge as the magnitude of the 
$f_{1}$ stimulus is increased ( $5 \mathrm{~A}$ top to bottom). Odd harmonics of the two frequencies interact with each other to generate higher frequency iDPs (right, gray bars).

Fig. 4B shows the magnitude of mechanical vibrations evoked by $\mathrm{FC}$ of the same $\mathrm{OHC}$ simulated in 4A under VC. The spectral pattern differs considerably, most notably with the addition of even harmonics not present in $\mathrm{VC}$ about $V^{p k}$. Furthermore, distortion products evoked by FC below BF are considerably larger than found in VC simulations, with the magnitude at $f_{2}-f_{1}$ approximately $45 \mathrm{~dB}$ below $f_{1}$ for $10 \mathrm{nN} \mathrm{FC}$ and $85 \mathrm{~dB}$ below for $10 \mathrm{mV} \mathrm{VC.}$ iDPs above BF emerge around odd harmonics for $\mathrm{VC} \sim 40 \mathrm{~dB}$ below $f_{1}$, but for both even and odd harmonics for FC. Although iDPs above BF are predicted to be present at the BF location in the cochlea, the vibrations would be expected to be trapped (evanescent) near the location of the OHC without generating DOPAEs in the ear canal. In contrast, OHCs located basal to BF would be expected to generate iDPs that propagate in the reverse direction and appear as DOPAEs in the ear canal.

To examine generation of iDPs by OHCs basal to BF, the cell shown in Figs. 4-5 was loaded with a $6 \mathrm{kHz}$ resonant spring-mass-damper and subjected to DP stimuli at $f_{1}=2 \mathrm{kHz}$ and $f_{2}=2.4 \mathrm{kHz}$. The simulation addresses iDP generation by an $\mathrm{OHC}$ located at the $6 \mathrm{kHz}$ place in response to a traveling waves exciting the more apical $2 \mathrm{kHz}$ place. The mechanical power output of the $\mathrm{OHC}$ in response to the $2 \mathrm{kHz}$ primary is $\sim 100 \mathrm{x}$ smaller in $\mathrm{VC}$ and $\sim 20 \mathrm{x}$ smaller in $\mathrm{FC}$ relative to stimulaton at the $6 \mathrm{kHz}$ BF (power output shown in Fig. 4p). Fig. 5 shows simulated iDP spectra in response to stimulation at $2 \mathrm{kHz}$, with results normalized relative to the peak. DPs were much smaller in magnitude (Fig. 4) but similar to spectra for stimulus frequencies centered near BF (e.g. Fig. 5). VC about $V^{p k}$ evoked odd harmonics with cubic two-tone distortion products dominating (6A), while FC evoked both even and odd iDPs (6B). Mechanical iDPs below BF associated with this cell (thick vs. thin bars in Fig. 5) would be expected to propagate in the reverse direction and appear in the ear canal as DOPAEs. Although iDPs generated by OHCs basal to BF are predicted to be much smaller than DPs generated near BF, they arise from virtually all OHCs and are predicted to supply power to reverse traveling waves at frequencies up to BF for each cell.

Results in Figs. 5 and 6 are consistent with the hypothesis that DPOAEs measured in the ear canal include iDPs generated near BF where amplification takes place, and iDPs generated basal to BF that contribute only modestly to amplification. The basal component is predicted to 
include both cubic and quadratic DPs below stimulus frequencies as well as even and odd harmonics above the stimulus frequencies, while the component near BF is predicted to be dominated by cubic DPs below the stimulus frequencies.

\section{Discussion}

Speed of the prestin-motor complex. Although it is well established that prestin is required for $\mathrm{OHC}$ somatic electromotility and cochlear amplification (Zheng, Shen et al. 2000, Liberman, Gao et al. 2002), precisely how OHCs deliver power to the cochlea at high auditory frequencies is unclear (He, Lovas et al. 2014). There is evidence that prestin-expressing OHCs operate at frequencies exceeding $120 \mathrm{kHz}$ in some mammals (Morell, Vogl et al. 2020), but several lines of evidence have challenged the notion of MET current driven cycle-by-cycle power output. Simple power analysis presented here and application to $\mathrm{OHC}$ data provides evidence that OHCs indeed output cycle-by-cycle power driven by MET current modulation across the frequency range of mammalian hearing. Results further explain how high-frequency power output is achieved by OHCs notwithstanding the low RC corner frequency (RC paradox (Housley and Ashmore 1992)) and low-pass character of real NLC (NLC speed paradox \{Santos-Sacchi, 2019 \#99;Santos-Sacchi, 2018 \#24).

The $R C$ paradox is resolved by considering how the prestin-motor complex consumes the receptor power provided by cycle-by-cycle MET gating (Eq. 3). Part of the receptor power is lost to heat through the resistive component of ionic currents (Eq. 4), while the rest is consumed by conversion to mechanical power output by the prestin-motor complex (Eq. 5) and by the electrical component of the bundle motor (Eq. 6). The present analysis shows the timing of motor charge displacement during the power stroke is phase shifted $90^{\circ}$ relative to the charge displacement in the passive membrane capacitance. This phase shift is undeniably required for power output (Eq. 2 and 7). Energy storage and release by passive membrane capacitance is orthogonal to power output by $\mathrm{OHC}$ electro-mechanical motors, and therefore has no impact on high-frequency function of $\mathrm{OHCs}$ as electro-mechanical motors. The phase shift is reflected on the mechanical side as well. Mechanical power output to a dissipative viscous load requires force to occur in phase with velocity (Eq. 13), which is consistent with voltage (as opposed to $d v / d t$ ) occurring in phase with the motor displacement current. Membrane conductance contributes to power loss (Eq. 4, Fig. 4A-B, p), but membrane capacitance and the RC corner are irrelevant to power output at peak frequency. Simple resolution of the $\mathrm{RC}$ paradox provided 
here is valid even if the extracellular voltage $v_{e}$ modulates cycle-by-cycle (which can be shown by replacing $v$ with by $v-v_{e}$, augmenting Eq. 1 with a second ODE describing $v_{e}$, and analyzing power for the coupled equations). Results further demonstrate that the MET receptor power is sufficient to drive high-frequency mechanical power output, and that cycle-by-cycle modulation of the extracellular voltage (putatively also driven by EP powered MET currents) is not required.

The NLC speed paradox is also resolved by simple power analysis. Initial reports of NLC focused on the real component $\left(\operatorname{Re}\left(C^{N}\right)\right)$ which dominates at low stimulus frequencies \{Gale, $1997 \# 90$. $\operatorname{Re}\left(C^{N}\right)$ and the magnitude $C^{N}$ indeed show low pass filtering in membrane patches beginning to roll off around $2 \mathrm{kHz}$, which is much too low to support cycle-by-cycle amplification across the auditory frequency spectrum. Low pass NLC led to the suggestion that voltage does not drive prestin (Santos-Sacchi and Tan 2019). Although $\operatorname{Re}\left(C^{N}\right)$ measures prestin expression, a simple power analysis shows $\operatorname{Re}\left(C^{N}\right)$ does not measure electro-mechanical power conversion or motor function (see Theory). Power output requires negative $\operatorname{Im}\left(C^{N}\right)$ (Eq. 7), which emerges only at high frequencies as $\operatorname{Re}\left(C^{N}\right) \rightarrow 0$ (Rabbitt 2020, Santos-Sacchi, Navaratnam et al. 2020). Although peak $\operatorname{Im}\left(C^{N}\right)$ is smaller than peak $\operatorname{Re}\left(C^{N}\right)$, the imaginary component occurring at high frequencies is sufficient to account for $\mathrm{OHC}$ and membrane patch cycle-by-cycle power output (Fig. 3). Emergence of $\operatorname{Im}\left(C^{N}\right)$ under voltage clamp conditions reveals a shift in the phase of the prestin-dependent charge displacement, which is in phase with $d v / d t$ at low frequencies (giving rise to real $\mathrm{NLC}$ ) and in phase with $v$ at high frequencies where maximum power conversion occurs (giving rise to imaginary NLC). The phase shift is required to align force with velocity and deliver mechanical power to the viscous load. In the context of electro-mechanical power conversion, experimental measurements showing roll-off of $\operatorname{Re}\left(C^{N}\right)$ with increasing frequency provide evidence for emergence of $\operatorname{Im}\left(C^{N}\right)$ and power output at high frequencies, as opposed to evidence for low pass motor function.

Impedance matching and importance of the cochlear load. Several theoretical reports have examined $\mathrm{OHC}$ power output under conditions simulating the mechanical load acting on OHCs in the cochlea (Rabbitt, Clifford et al. 2009, O Maoiléidigh and Hudspeth 2013, Iwasa 2016, Rabbitt 2020). Although reports differ considerably in approach and details, all reach the same conclusion: the cochlear load is critical to the ability of OHCs to deliver power to the cochlea. For a spring-mass-damper system, which is a simple model of the cochlear load acting on an 
$\mathrm{OHC}$, the maximum power delivery occurs when the load is forced at its natural frequency $\omega_{0}$, which is the frequency where the inertial and elastic forces balance and the mechanical impedance of the load $\left(Z^{L}\right)$ is dominated by viscous drag. To deliver power to a resonant load in the cochlea the $\mathrm{OHC}$ must have the ability to output force and velocity at the natural frequency of the load, which is accomplished with maximum efficiency when the mechanical impedance of the load matches the impedance of the cell $\left(Z^{C}\right.$, determined by both electrical and mechanical properties). Impedance matching is hypothetically achieved in the cochlea by optimizing $\mathrm{OHC}$ and organ of Corti physical properties (e.g. stiffnesses, length, prestin expression, conductance...). To what extent impedance matching is actually achieved in the cochlea is beyond the scope of the present report, but simulations (Fig. 4C) indicate $\mathrm{OHC}$ impedance matching to the cochlear load is likely to be excellent at BF $\left(\omega_{o}\right)$, resulting in over $70 \%$ electro-mechanical conversion efficiency. For results in Fig. 4, efficiency is the mechanical power output ( $p$, black) divided by the electrical power input ( $p$, green), in this case simulated as a function of frequency for a fixed load and fixed $\mathrm{OHC}$ parameters. For the parameters used in the present study, the prestin-motor complex itself does not dissipate significant heat (i.e. $\tau^{p}$ in Eq. A1 is small), and as a result the electrical power consumed (Eq. 5 or 7 ) is indistinguishable from the mechanical power output Eq. 13). The efficiency and speed of the prestin motor itself could revealed in future by simultaneous measurement of electrical power consumption and mechanical power output .

OHC Distortion Products. OCT measurements of vibrations with the organ of Corti by Cooper et al.(2018) (Cooper, Vavakou et al. 2018) demonstrate two nonlinearities, one that is responsible for amplification near BF and the second that occurs broadly at locations in the cochlea basal to BF. Results are consistent with measurements by Dewy et al. (Dewey, Applegate et al. 2019) demonstrating that amplification of the traveling wave occurs primarily near the peak. These two intracochlear nonlinearities likely underlie signature properties of OAEs measured in the ear canal (Kemp and Brown 1983, Shera 2004). The present work suggests both nonlinearites arise from the same $\mathrm{OHC}$ biophysics, and differ primarily by the ability of the $\mathrm{OHC}$ to drive the local cochlear load and the extent to which traveling waves (vs. evanescent modes) are excited by OHC iDP vibrations.

\section{Acknowledgement}

Support was provided by the National Institutes on Deafness and other Communication Disorders grant R01 DC006685. 
bioRxiv preprint doi: https://doi.org/10.1101/2021.07.29.454372; this version posted July 29, 2021. The copyright holder for this preprint (which was not certified by peer review) is the author/funder. All rights reserved. No reuse allowed without permission. 


\section{Appendix}

\section{D Nonlinear Piezoelectric Model.}

Following Rabbitt (Rabbitt 2020), the OHC lateral wall is treated as a composite consisting of two distinct domains: a passive membrane domain " $m$ " and an active domain " $p$ " containing the prestin-motor complex. The domains are in parallel electrically and in series mechanically. In the simple 1D model, the whole-cell displacement is the addition of displacement in the motor domain plus the passive domain $x=x^{p}+x^{m}$. A linear viscoelastic model is used for the passive domain:

$$
\frac{\tau^{m}}{\ell \kappa^{m}} \frac{d x^{m}}{d t}+\frac{1}{\ell \kappa^{m}} x^{m}-f^{c}=0
$$

where $b$ is the axial force in the $\mathrm{OHC}, \ell$ is the cell length, $\kappa^{m}$ is the compliance of the passive domain and $\tau^{m}$ is the viscoelastic relaxation time of the passive domain. The prestin-motor domain is treated as visco-piezoelectric membrane using the stress-charge form:

$$
\frac{\tau^{P}}{\ell \kappa^{p}} \frac{d x^{p}}{d t}+\frac{1}{\ell \kappa^{p}} x^{p}-f^{c}-\frac{\delta}{\kappa^{p}} \mathrm{v}=0
$$

where $\kappa^{p}$ is the compliance and $\tau^{p}$ is the intrinsic time constant (speed) of motor function. $\delta$ is the piezoelectric strain coefficient, which is a function of strain in the prestin-motor complex and approaches zero as the voltage and/or force moves away from its optimum operating point $\left(v^{p k}, f^{p k}\right)$. The nonlinear dependence of the piezoelectric coefficient on strain is written

$$
\delta=\delta^{p k} \Lambda
$$

where the function $\Lambda=\Lambda(\xi)$ describes the strain-dependent saturation of the charge displacement, which putatively arises from conformational changes in prestin saturating at fully extended and contracted extremes. The nondimensional strain under isothermal conditions is written in terms of voltage and force as

$$
\xi(v, f)=\frac{1}{\delta \lambda}\left(s^{p}-s^{p k}\right)=\frac{1}{\lambda}\left(\left(v-v^{p k}\right)+\frac{\kappa^{p}}{\delta^{p k}}\left(f^{c}-f^{p k}\right)\right)
$$


The voltage sensitivity is $\lambda=\frac{k_{B} \theta_{0}}{z e}$, where $\theta_{0}$ is absolute temperature, $k_{B}$ is Boltzmann's constant, $z e$ is the maximum charge movement between saturated extended and contracted states. Saturation arising from strain is approximated here using the first derivative of the Langevin function:

$$
\Lambda(\xi)=\sqrt{3\left(\frac{1}{\xi^{2}}-\operatorname{Csch}(\xi)^{2}\right)},
$$

NLC arises from the strain dependent piezoelectric coefficient and, if the $\mathrm{OHC}$ is unloaded, the NLC measured under voltage clamp is $C^{N}=C^{p k} \Lambda^{2}$ (note: $C^{N}$ is proportional to $\Lambda^{2}$ while $\delta$ is proportional to $\Lambda$ ).

The displacement of the load is equal to the lengthening of the $\mathrm{OHC} x=x^{p}+x^{m}$, and resisted by a spring-mass-damper system:

$$
\left(\frac{K^{L}}{\omega_{0}^{2}}\right) \frac{d^{2} x}{d t^{2}}+\left(\frac{2 K^{L} \zeta^{L}}{\omega_{o}^{n}}\right) \frac{d^{n} x}{d t^{n}}+K^{L} x+f^{c}+f^{b} / r=f
$$

where $K^{L}$ is the stiffness, $\omega_{0}$ is the natural frequency, $\zeta^{L}$ is the nondimensional damping coefficient, " $n$ " is the power-law damping fractional derivative, $f^{c}$ is the intrinsic force generated by the prestin-motor complex, $f^{b}$ is the force from active bundle movement and $f$ is the extrinsic axial force applied to the system.

Based on a modified gating spring model (Kennedy, Crawford et al. 2005) the bundle force is related to displacement by

$$
x^{b}-a\left(p\left(x^{g}\right)-p(0)\right)=\left(f^{b}-c^{b}\left(v-v_{o}\right)\right) / k^{b}
$$

where $p$ is the MET channel open probability, $f^{b}$ is the force driving bundle displacement $k^{b}$ ( 3 $m N m-1$ (Kennedy, Crawford et al. 2005)) is the stiffness and $c^{b}$ is the bundle piezoelectric force coefficient. To fit OHC stiffness data, Kennedy et al. (2005) (Kennedy, Crawford et al. 2005) required the parameter $a$ to be orders of magnitude larger than channel opening swing (1-4 $\mathrm{nm})$ -- consistent with this, present results use $a=300 \mathrm{~nm}$. 
The open probability is related to the MET current by: $i=i_{\max } P\left(x^{g}\right)$, where

$$
P\left(x^{g}\right)=\left(1+\exp \left(-\left(x_{g}-x_{o}\right) / x_{e}\right)\right)^{-1}
$$

with $i_{\text {max }} \approx 0.6 n A, x_{o} \approx 300 \mathrm{~nm}$ and $x_{e} \approx 100 \mathrm{~nm}$ (Kennedy, Crawford et al. 2005). Following an approach similar to (O Maoiléidigh and Jülicher 2010) MET adaptation is modeled by introducing an intermediate displacement

$$
\tau_{a} \frac{d x^{a}}{d t}+x^{a}=x^{L} / r
$$

where $\tau_{a}$ is the adaptation time. Adaptation of channel gating is modeled using

$$
x^{g}=\phi\left(x^{a}+\tau_{g} \frac{d x^{a}}{d t}\right)
$$

where $\phi$ is a gain and $\tau_{g}$ defines the extent of adaptation.

In the time domain, Kirchoff's current law relates the MET current, conduction currents and displacement currents to changes in voltage by:

$$
c^{m} \frac{d v}{d t}+c^{s} \frac{d x^{s}}{d t}+c^{b} \frac{d x^{b}}{d t}+i^{i}=i
$$

where the ionic currents for small perturbations are written using the tangent conductances: $i^{i}=g^{b} b+g^{m} v$.

Linearized 1D Piezoelectric Analysis. The above equations can be linearized to examine hypothetical power output of OHCs in the context of the cochlear load. The frequency domain matrix equations for small perturbations are provided below. Eqs A9-A12 give the matrix equation forms followed by definitions of linearized terms in Eqs A13-18.

A. Voltage Clamp, MET blocked. The linearized equations for ideal voltage clamp are: 


$$
\left[\begin{array}{cccc}
D^{P} & 0 & 0 & -1 \\
0 & D^{M} & 0 & -1 \\
1 & 1 & -1 & 0 \\
0 & 0 & D^{L} & 1
\end{array}\right]\left[\begin{array}{c}
X^{P} \\
X^{M} \\
X^{L} \\
F^{C}
\end{array}\right]=\left[\begin{array}{c}
C^{P} V \\
0 \\
0 \\
0
\end{array}\right]
$$

B. Current Clamp, MET blocked. The linearized equations for ideal current clamp are:

$$
\left[\begin{array}{ccccc}
D^{P} & 0 & 0 & -1 & -C^{P} \\
0 & D^{M} & 0 & -1 & 0 \\
1 & 1 & -1 & 0 & 0 \\
0 & 0 & D^{L} & 1 & 0 \\
j \omega C^{P} & 0 & 0 & 0 & j \omega C^{L}+G^{L}
\end{array}\right]\left[\begin{array}{c}
X^{P} \\
X^{M} \\
X^{L} \\
F^{S} \\
V
\end{array}\right]=\left[\begin{array}{l}
0 \\
0 \\
0 \\
0 \\
I
\end{array}\right]
$$

C. Force Clamp, MET blocked. The linearized equations for ideal force clamp are:

$$
\left[\begin{array}{ccccc}
D^{P} & 0 & 0 & -1 & -C^{P} \\
0 & D^{M} & 0 & -1 & 0 \\
1 & 1 & -1 & 0 & 0 \\
0 & 0 & D^{L} & 1 & 0 \\
j \omega C^{P} & 0 & 0 & 0 & j \omega C^{L}+G^{L}
\end{array}\right]\left[\begin{array}{c}
X^{P} \\
X^{M} \\
X^{L} \\
F^{S} \\
V
\end{array}\right]=\left[\begin{array}{c}
0 \\
0 \\
0 \\
F \\
0
\end{array}\right]
$$

D. Force Clamp, with MET gated by bundle displacement. The linearized equations for ideal force driven $\mathrm{OHC}$ electromechanics are:

$$
\left[\begin{array}{ccccccc}
D^{P} & 0 & 0 & -1 & -C^{P} & 0 & 0 \\
0 & D^{M} & 0 & -1 & 0 & 0 & 0 \\
1 & 1 & -1 & 0 & 0 & 0 & 0 \\
0 & 0 & D^{L} & 1 & 0 & 0 & 1 \\
j \omega C^{P} & 0 & -D^{I} / r & 0 & j \omega C^{L}+G^{L} & j \omega D^{G} C^{B} & 0 \\
0 & 0 & -1 / r & 0 & 0 & D^{G} & 0 \\
0 & 0 & -K^{B} / r & 0 & -C^{B} & a s K^{B} & 1
\end{array}\right]\left[\begin{array}{c}
X^{P} \\
X^{M} \\
X^{L} \\
F^{S} \\
V \\
X^{G} \\
F^{B}
\end{array}\right]=\left[\begin{array}{c}
0 \\
0 \\
0 \\
F \\
0 \\
0 \\
0
\end{array}\right]
$$

Electromechanics and speed of the prestin-motor complex is determined by:

$$
\begin{aligned}
& D^{P} X^{P}=F^{C}+C^{P} V \\
& D^{P}=\frac{1}{\ell \kappa^{P}}\left(1+\tau^{P} j \omega\right)
\end{aligned}
$$


where $\tau^{P}$ is the relaxation time constant and $C^{P}=\delta^{p} / \kappa^{P}$ is the piezoelectric force coefficient. Visco-elastic behavior of the unloaded passive membrane domain is modeled using:

$$
\begin{aligned}
& D^{M} X^{M}=F^{C} \\
& D^{M}=\frac{1}{\ell \kappa^{M}}\left(1+\tau^{M} j \omega\right)
\end{aligned}
$$

where $\kappa^{M}$ is the compliance of the passive domain, $\tau^{M}$ is the relaxation time constant. Eqs. A13-14 are first order differential equations coupled in series, which is mathematically equivalent to transition state theory if the prestin-motor complex has three primary states (assuming $n=1$ ).

Although Eq. A13 sets the speed of the unloaded prestin-motor complex, the speed under physiological conditions is limited by properties of the load, rather than limited by the motor itself. From Eq. 7. the load is described in the frequency-domain by $D^{L}$, which related the load displacement to the summation of the applied force and forces from the bundle and soma

$$
\begin{aligned}
& D^{L} X^{L}+F^{S}+F^{B}=F \\
& D^{L}=K^{L}\left(2 \zeta^{L}\left(\frac{j \omega}{\omega_{o}}\right)^{n}+1-\left(\frac{\omega}{\omega_{o}}\right)^{2}\right) .
\end{aligned}
$$

$D^{L}$ represents the combination of the cell itself, the media and the extrinsic load.

Combining Eq. A9 and A10, the MET channel gating variable is defined by an adaptation operator

$$
\begin{aligned}
& D^{G} X^{G}=X^{B}=X^{L} / r \\
& D^{G}=\frac{\left(1+\tau^{a} j \omega\right)}{\phi\left(1+\tau^{g} j \omega\right)}
\end{aligned}
$$

where $\tau^{a}$ is the adaptation time constant and $r$ is a kinematic lever ratio relating steady state transverse bundle displacement to axial $\mathrm{OHC}$ displacement. $\phi$ is a gain and $\tau^{g}$ determines the extent and frequency dependence of adaptation.

The linearized transduction current is related to the gating displacement by 


$$
\begin{aligned}
& I=P\left(X^{G}\right) \rightarrow D^{I} X^{L} / r \\
& D^{I}=I_{m} s \frac{\phi\left(1+\tau^{g} j \omega\right)}{\left(1+\tau^{a} j \omega\right)}=\frac{I_{m} s \phi}{1+\left(\tau^{a} \omega\right)^{2}}\left(\left(1+\tau^{g} \tau^{a} \omega^{2}\right)+\left(\tau^{g}-\tau^{a}\right) \mathrm{j} \omega\right)
\end{aligned}
$$

where $I_{m}$ is the maximum MET current and $s$ is the slope of the open probability at $x^{g}=0$, $\mathrm{s}=x_{e}^{-1} e^{\left(x_{o} / x_{e}\right)}\left(1+e^{\left(x_{o} / x_{e}\right)}\right)^{-2}$. The linearized equations can be unstable for certain parameter selections because the imaginary part of Eq. A17 can introduce negative damping for certain values of $\tau^{g}$ and $\tau^{a}$. A Taylor series expansion of Eq. A7 provides the linearized force arising from MET gating as

$$
F^{B}=\left(K^{B} / r\right) X^{L}-\left(a s K^{B}\right) X^{G}+C^{B} V .
$$

Mechanical power output by the hair bundle is found by multiplying the force $F^{B}$ by the complex conjugate of velocity and taking half of the real part:

$$
P_{B}=\frac{1}{2} \operatorname{Re}\left(F^{B}\left(j \omega X^{B}\right)^{*}\right)
$$

which reduces in the linearized case to

$$
P_{B}=\frac{a s K^{B}}{2} \operatorname{Im}\left(X^{G} X^{B^{*}}\right)+\frac{-C^{B} \omega}{2} \operatorname{Im}\left(V X^{B^{*}}\right) .
$$

\section{Figure Captions}

Fig. 1. Cartoon of $\mathrm{OHC}$ electro-mechanics under load. A). Mechanical load driven by extrinsic force " $f$ " (pressure), OHC somatic motor force " $f$ " and bundle force " $f$ ". . Displacement " $x$ " of the load opens MET channels leading to transduction current " $i$ ", voltage " $v$ " and charge displacement " $q$ ". The charge displacement is coupled to the $\mathrm{OHC}$ force and to the voltage, and the MET current is coupled to the $\mathrm{OHC}$ force and the status of the channels. Nonlinearites arise from NLC and MET. MET current (right) is high-pass, saturates as the displacement increases, and reduces stiffness during MET opening (based on Fettiplace 2017). NLC (left) is band-pass, reduces as the voltage deviates from " $V^{p k}$ ", and shifts phase as frequency is increased (based on Rabbitt 2020 and Santos-Sacchi et al. 2020). 
Fig. 2. Isolated $\mathrm{OHC}$ power output $\left(P_{M}\right)$ in the $\mu$-chamber. A). $\mu$-chamber used to apply sinusoidal voltages with the $\mathrm{OHC}$ partially extending into media. B-C) Magnitude and phase of the displacement $X$ measured by Frank et al. (Frank, Hemmert et al. 1999) for cells of two different lengths extending outside the chamber (symbols). Solid curves are curve-fits used to estimate the dissipation parameters $c$ and $n$ (Rabbitt 2021). D) Mechanical power output was estimated from Eq. 12 and measured displacement $X$. Power output for the longer cell peaked at $32 \mathrm{kHz}$ with a value of $230 \mathrm{fW}-\mathrm{mV}^{-2}$, and for the shorter cell peaked at $74 \mathrm{kHz}$ with a value of $150 \mathrm{fW}-\mathrm{mV}^{-2}$. The peak power output occurs when the phase of the displacement is $-90^{\circ}$ relative to the peak sinusoidal voltage.

Fig. 3. OHC membrane patch power conversion $\left(P_{C}\right)$. A) Real NLC, $\operatorname{Re}\left(C^{V}\right)$, in OHC macropatches reported by Gale \& Ashmore (symbols) (Gale and Ashmore 1997) and curve-fit to a 1D piezoelectric theory (Rabbitt 2021). B) $\operatorname{Im}\left(C^{V}\right)$ estimated from the curve-fit and C) electrical power consumed by the prestin-motor complex. By conservation of energy, electrical power consumed is equal to the power dissipated by the membrane patch plus the power delivered to the extrinsic media. D) Voltage and frequency dependence of NLC estimated for the macropatch based on the Gale \& Ashmore data.

Fig. 4. Simulated OHC power output under cochlear load. Power output of $25 \mu m$ long OHC subject to an extrinsic spring-mass-damper load with a best frequency (BF) of $6 \mathrm{kHz}$ was simulated under A) voltage clamp (VC), B) current clamp (CC) and C) extrinsic force clamp (FC). Panels show magnitude of displacement (d), current (i), voltage (v), somatic force (b), phase (rad) and power (p). Power is reported as: input via the electrode or MET current and consumed by the cell (green) and output to the extrinsic viscous load (output, black). Results are shown for a low membrane $\mathrm{R}$ (thin curves, high $\mathrm{RC}$ corner frequency) and a high membrane $\mathrm{R}$ (thick curves, low RC corner frequency). A) $1 \mathrm{mV}$ VC showing peak displacement and power output near BF. The current (i, solid) increases above the $\mathrm{RC}$ corner, but the passive capacitive current and does not consume power or metabolic energy ( $p$, green line is flat). B) 1 nA CC showing peak displacement and power output near BF. Voltage decreases above the RC corner. C) $1 \mathrm{pN}$ force clamp (see Fig. 1, " $f$ " applied to extrinsic load) with the MET current assumed proportional to the rate of change of force " $b$ " between the $\mathrm{OHC}$ and the extrinsic load. During FC, displacement, voltage, current, force and power are all band pass and tuned to BF. 
Fig. 5. Distortion products generated by OHCs near BF. Response of a $25 \mu \mathrm{m}$ long OHC stimulated in voltage clamp and loaded by a spring-mass-damper system located near $\mathrm{BF}=6 \mathrm{kHz}$. Fourier components of $\mathrm{OHC}$ displacement are shown as $\mathrm{dB}$ relative to the peak $6 \mathrm{kHz}$ component. A) Fourier components of $\mathrm{OHC}$ displacement in response to sinusoidal VC at $f_{2}=7.2 \mathrm{kHz}$ centered around the holding potential $v^{p k}$. Nonlinearity of prestin-motor complex gives rise to odd harmonics at $3 f_{2}$ and $5 f_{2}$. Introduction of a primary sinusoidal stimulus at $f_{1}=6 \mathrm{kHz}$ gives rise to cubic distortion products below the primary, as well as corresponding DPs above the secondary. DPs at frequencies below the secondary (thick bars) would be expected to generate propagating waves with the reverse component appearing as DPOAEs in the ear canal. DPs are also predicted to be evoked by interaction of odd harmonics above BF (thin gray bars). DPs at frequencies above BF would be expected to generate evanescent vibrations trapped near the OHC that would not appear as DPOAEs in the ear canal. Growth of DPs and emergence of DPs is shown from top to bottom as the amplitude of the primary is increased from 0 to $10 \mathrm{mV}$. B) Fourier components of $\mathrm{OHC}$ displacement in response to sinusoidal FC presented in the same format as VC (A).

Fig. 6. Distortion products generated by OHCs basal to BF. Mechanical DPs for the same cell simulated in Fig. 5 and located at $6 \mathrm{kHz} \mathrm{BF}$, but stimulated at $f_{1}=2 \mathrm{kHz}$ and $f_{2}=2.2 \mathrm{kHz}$. Vibrational amplitudes are shown relative to the peak at $f_{1}=2 \mathrm{kHz}$. A) DPs generated by VC and B) FC at frequencies below BF are predicted to be similar to those generated by stimuli near BF but with power output per cell an order of magnitude lower (Fig. 4 p). DPs below BF (thick bars) would be expected to generate propagating waves with the reverse component appearing as DPOAEs in the ear canal. 
Table 1: Parameters

\begin{tabular}{|c|c|c|c|c|}
\hline Symbol & $\begin{array}{l}\text { Value } \\
\text { (SI Units) }\end{array}$ & Description & $\begin{array}{l}\text { Present } \\
\text { Estimation } \\
\text { Method }\end{array}$ & $\begin{array}{l}\text { Data } \\
\text { Source }\end{array}$ \\
\hline$a$ & $\begin{array}{l}300 \times 10^{-9} \\
(\mathrm{~m})\end{array}$ & $\begin{array}{l}\text { Bundle negative stiffness } \\
\text { parameter }\end{array}$ & - & $\begin{array}{l}\text { (Kennedy, } \\
\text { Crawford et al. } \\
2005)\end{array}$ \\
\hline$C_{E}^{L}$ & $\begin{array}{l}\text { variable } \\
(\mathrm{F})\end{array}$ & $\begin{array}{l}\text { Linear electrical capacitance } \\
(\sim 22 \mathrm{pF} \text { for } 25 \mu \mathrm{m} \text { long } \mathrm{OHC})\end{array}$ & $\begin{array}{l}\text { OHC size } \\
\text { dependent }(\sim \\
\left.1 \mu \mathrm{F}-\mathrm{cm}^{2}\right)\end{array}$ & $\begin{array}{l}\text { (Iwasa 1993, } \\
\text { Santos-Sacchi, } \\
\text { Shen et al. 2001) }\end{array}$ \\
\hline$C_{E}^{p k}$ & $\begin{array}{l}\text { variable } \\
(\mathrm{F})\end{array}$ & $\begin{array}{l}\text { Peak NLC arises from } \delta^{p k} \\
(\sim 24 \mathrm{pF} \text { for } 25 \mu \mathrm{m} \text { long } \mathrm{OHC}) \text {. }\end{array}$ & From $\delta^{p k}$ & - \\
\hline$c^{b} / k^{b}$ & $\begin{array}{l}4.8 \times 10^{-6} \\
\left(\mathrm{~m} \mathrm{~V}^{-1}\right)\end{array}$ & $\begin{array}{l}\text { Bundle piezoelectric strain } \\
\text { coefficient }\end{array}$ & - & (Jia and He 2005) \\
\hline$k^{b}$ & $\begin{array}{l}0.002 \\
\left(\mathrm{~N} \mathrm{~m}^{-1}\right)\end{array}$ & Bundle stiffness & - & $\begin{array}{l}\text { (Kennedy, } \\
\text { Crawford et al. } \\
\text { 2005) }\end{array}$ \\
\hline$l_{c}$ & $\begin{array}{l}2,54 \times 10^{-6} \\
(\mathrm{~m})\end{array}$ & $\begin{array}{l}\text { Hair cell length. Cochlear } \\
\text { place dependent. }\end{array}$ & Near $6 \mathrm{kHz}$ place & $\begin{array}{l}\text { (Pujol, Lenoir et } \\
\text { al. 1992) }\end{array}$ \\
\hline$n$ & $\begin{array}{l}0.7 \\
(-)\end{array}$ & $\begin{array}{l}\text { Fractional derivative } \\
\text { governing relaxation } \\
\text { spectrum. }\end{array}$ & $\begin{array}{l}\text { From power law } \\
\text { frequency roll-off } \\
\text { of the real NLC. }\end{array}$ & $\begin{array}{l}\text { (Gale and } \\
\text { Ashmore 1997, } \\
\text { Santos-Sacchi } \\
\text { and Tan 2019) }\end{array}$ \\
\hline$r$ & $\begin{array}{c}6 \\
(-)\end{array}$ & Kinematic lever ratio & $\begin{array}{l}\text { Ratio of OHC } \\
\text { axial displacement } \\
\text { to bundle } \\
\text { transverse } \\
\text { displacement }\end{array}$ & $\begin{array}{l}\text { (Fridberger, Tomo } \\
\text { et al. 2006) }\end{array}$ \\
\hline$V^{p k}$ & $\begin{array}{c}-0.047 \\
(\mathrm{~V})\end{array}$ & Voltage of peak NLC & Curve fit NLC data & $\begin{array}{l}\text { (Kakehata and } \\
\text { Santos-Sacchi } \\
\text { 1995) }\end{array}$ \\
\hline$z_{e}$ & $\begin{array}{l}100 \times 10^{-9} \\
(\mathrm{~m})\end{array}$ & Open probability parameter & - & $\begin{array}{l}\text { (Kennedy, } \\
\text { Crawford et al. } \\
\text { 2005) }\end{array}$ \\
\hline$z_{o}$ & $\begin{array}{l}300 \times 10^{-9} \\
(\mathrm{~m})\end{array}$ & Open probability parameter & - & $\begin{array}{l}\text { (Kennedy, } \\
\text { Crawford et al. } \\
\text { 2005) }\end{array}$ \\
\hline$\delta^{p k}$ & $\begin{array}{c}-0.1558 \\
\left(V^{-1}\right)\end{array}$ & $\begin{array}{l}\text { Piezoelectric strain } \\
\text { coefficient at } V^{p k}\end{array}$ & $\begin{array}{c}\text { From } \delta^{p k} / \kappa^{p} \text { and } \\
\kappa^{p}\end{array}$ & $\begin{array}{l}\text { (Hallworth 1995, } \\
\text { Iwasa and Adachi } \\
\text { 1997, Dong, } \\
\text { Ospeck et al. } \\
\text { 2002) }\end{array}$ \\
\hline$\delta^{p k} / \kappa^{p}$ & $\begin{array}{c}-1.5 \times 10-7 \\
\left(\mathrm{~N} \mathrm{~V}^{-1}\right)\end{array}$ & $\begin{array}{l}\text { Piezoelectric stress } \\
\text { coefficient at } V^{p k}\end{array}$ & $\begin{array}{l}\text { From isometric } \\
\text { stress }(\mathrm{nN} / \mathrm{mV}) \\
\text { and whole cell } \\
\text { strain }\left(\mathrm{mV}^{-1}\right)\end{array}$ & $\begin{array}{l}\text { (Hallworth 1995, } \\
\text { Iwasa and Adachi } \\
\text { 1997, Dong, } \\
\text { Ospeck et al. } \\
\text { 2002) }\end{array}$ \\
\hline$\kappa^{m}$ & $\begin{array}{c}\kappa^{p} / 10 \\
\left(\mathrm{~N}^{-1}\right)\end{array}$ & $\begin{array}{l}\text { Compliance of passive } \\
\text { domain }\end{array}$ & $\begin{array}{l}\text { Assume 10x } \\
\text { reduction in NLC } \\
\text { under isometric } \\
\text { vs. isotonic } \\
\text { conditions }\end{array}$ & - \\
\hline$\kappa^{p}$ & $1.038 \times 10^{6}$ & Compliance of prestin & Based on whole & (Frank, Hemmert \\
\hline
\end{tabular}




\begin{tabular}{|c|c|c|c|c|}
\hline & $\left(\mathrm{N}^{-1}\right)$ & domain & cell compliance & $\begin{array}{l}\text { et al. 1999, He } \\
\text { and Dallos 1999, } \\
\text { He and Dallos } \\
2000)\end{array}$ \\
\hline$\lambda$ & $\begin{array}{c}0.032 \\
(\mathrm{~V})\end{array}$ & Voltage sensitivity & $\begin{array}{l}\text { Curve fit low } \\
\text { frequency NLC } \\
\text { data }\end{array}$ & $\begin{array}{l}\text { (Kakehata and } \\
\text { Santos-Sacchi } \\
\text { 1995, Santos- } \\
\text { Sacchi and Tan } \\
\text { 2019) }\end{array}$ \\
\hline$\phi$ & $\begin{array}{l}10 \\
(-)\end{array}$ & $\begin{array}{l}\text { MET gating adaptation gain } \\
\text { parameter }\end{array}$ & $\begin{array}{l}\text { Based on MET } \\
\text { current adaption }\end{array}$ & $\begin{array}{l}\text { (Kennedy, } \\
\text { Crawford et al. } \\
\text { 2005) }\end{array}$ \\
\hline$\tau^{a}$ & $\begin{array}{c}0.00167 \\
(s)\end{array}$ & MET adaptation time const. & Fit adaptation. & $\begin{array}{l}\text { (Kennedy, } \\
\text { Crawford et al. } \\
\text { 2005) }\end{array}$ \\
\hline$\tau^{g}$ & $\begin{array}{l}0.033 \\
(\mathrm{~s})\end{array}$ & $\begin{array}{l}\text { Determines the extent of } \\
\text { MET current adaptation for a } \\
\text { step bundle displacement. }\end{array}$ & $\begin{array}{l}\text { Based on MET } \\
\text { current adaption }\end{array}$ & $\begin{array}{l}\text { (Kennedy, } \\
\text { Crawford et al. } \\
\text { 2005, Szalai, } \\
\text { Tsaneva- } \\
\text { Atanasova et al. } \\
\text { 2011) }\end{array}$ \\
\hline$\tau^{p}$ & $\begin{array}{c}2 \times 10^{-1} \\
(\mathrm{~s})\end{array}$ & $\begin{array}{l}\text { Relaxation time constant of } \\
\text { piezoelectric domain }\end{array}$ & $\begin{array}{l}\text { Lack of corner in } \\
\text { Bode force up to } \\
80 \mathrm{kHz} \text {. }\end{array}$ & $\begin{array}{l}\text { (Frank, Hemmert } \\
\text { et al. 1999) }\end{array}$ \\
\hline$\tau^{m}$ & $\begin{array}{c}\tau^{p} / 10 \\
(\mathrm{~s})\end{array}$ & $\begin{array}{l}\text { Relaxation time constant } \\
\text { passive domain }(\sim 0)\end{array}$ & $\begin{array}{l}\text { Assume relaxation } \\
\text { arises from prestin } \\
\text { domain }\end{array}$ & - \\
\hline$\tau_{R C}$ & $\begin{array}{l}\text { variable } \\
(\mathrm{s})\end{array}$ & $\begin{array}{l}\text { Passive electrical time } \\
\text { constant of the OHC. OHC } \\
\text { size and location dependent. }\end{array}$ & $\begin{array}{l}\text { Varied in Fig. } 4 \text { for } \\
\text { illustration }\end{array}$ & $\begin{array}{l}\text { (Muller 1996, } \\
\text { Johnson, Beurg et } \\
\text { al. 2011) }\end{array}$ \\
\hline$\omega_{n}$ & $\begin{array}{l}22619 \\
\left(\operatorname{rad~s}^{-1}\right)\end{array}$ & $\begin{array}{l}\text { Natural frequency of the } \\
\text { cochlear load at the tonotopic } \\
\text { place for } 25 \mu \mathrm{m} \mathrm{OHC}(6 \mathrm{kHz})\end{array}$ & $\begin{array}{l}\text { Defined by } \\
\text { cochlear place } \\
\text { principle. }\end{array}$ & $\begin{array}{l}\text { (Pujol, Lenoir et } \\
\text { al. 1992, Muller } \\
\text { 1996) }\end{array}$ \\
\hline$\zeta$ & $\begin{array}{c}0.56 \\
(-)\end{array}$ & $\begin{array}{l}\text { Nondimensional damping } \\
\text { coef. of the load }\end{array}$ & $\begin{array}{l}\text { Underdamped } \\
\text { based on passive } \\
\text { cochlear tuning. }\end{array}$ & $\begin{array}{l}\text { (Cormack, Liu et } \\
\text { al. 2015, Altoe } \\
\text { and Shera 2020) }\end{array}$ \\
\hline
\end{tabular}




\section{Citations}

Altoe, A. and C. Shera (2020). "Nonlinear cochlear mechanics without direct vibrationamplification feedback." Phys. Rev. Research 2(1): 20.

Anniko, M. and R. Wroblewski (1986). "Ionic environment of cochlear hair cells." Hear Res 22: 279-293.

Ashmore, J. (2019). "Outer Hair Cells and Electromotility." Cold Spring Harb Perspect Med 9(7).

Ashmore, J. F. (1987). "A fast motile response in guinea-pig outer hair cells: the cellular basis of the cochlear amplifier." J Physiol 388: 323-347.

Beurg, M., M. G. Evans, C. M. Hackney and R. Fettiplace (2006). "A large-conductance calciumselective mechanotransducer channel in mammalian cochlear hair cells." J Neurosci 26(43): 10992-11000.

Beurg, M., R. Fettiplace, J. H. Nam and A. J. Ricci (2009). "Localization of inner hair cell mechanotransducer channels using high-speed calcium imaging." Nat Neurosci 12(5): 553-558.

Beurg, M., J. H. Nam, Q. Chen and R. Fettiplace (2010). "Calcium balance and mechanotransduction in rat cochlear hair cells." J Neurophysiol 104(1): 18-34.

Beurg, M., J. H. Nam, A. Crawford and R. Fettiplace (2008). "The actions of calcium on hair bundle mechanics in mammalian cochlear hair cells." Biophys J 94(7): 2639-2653.

Bosher, S. K. and R. L. Warren (1971). "A study of the electrochemistry and osmotic relationships of the cochlear fluids in the neonatal rat at the time of the development of the endocochlear potential." J Physiol 212(3): 739-761.

Bosher, S. K. and R. L. Warren (1978). "Very low calcium content of cochlear endolymph, an extracellular fluid." Nature 273(5661): 377-378.

Brownell, W. E., C. R. Bader, D. Bertrand and Y. de Ribaupierre (1985). "Evoked mechanical responses of isolated cochlear outer hair cells." Science 227(4683): 194-196.

Chen, Q., S. Mahendrasingam, J. A. Tickle, C. M. Hackney, D. N. Furness and R. Fettiplace (2012). "The development, distribution and density of the plasma membrane calcium ATPase 2 calcium pump in rat cochlear hair cells." Eur J Neurosci 36(3): 2302-2310.

Cooper, N. P., A. Vavakou and M. van der Heijden (2018). "Vibration hotspots reveal longitudinal funneling of sound-evoked motion in the mammalian cochlea." Nat Commun 9(1): 3054. 
Cormack, J., Y. Liu, J. H. Nam and S. M. Gracewski (2015). "Two-compartment passive frequency domain cochlea model allowing independent fluid coupling to the tectorial and basilar membranes." J Acoust Soc Am 137(3): 1117-1125.

Corns, L. F., S. L. Johnson, C. J. Kros and W. Marcotti (2014). "Calcium entry into stereocilia drives adaptation of the mechanoelectrical transducer current of mammalian cochlear hair cells." Proc Natl Acad Sci U S A 111(41): 14918-14923.

Cross, R. A. (2004). "The kinetic mechanism of kinesin." Trends Biochem Sci 29(6): 301-309.

Curie, J. and P. Curie (1881). "Contractions and expansions produced by voltages in hemihedral crystals with inclined faces,." Comptes Rendus 93: 1137-1140.

Dallos, P. and M. A. Cheatham (1976). "Production of cochlear potentials by inner and outer hair cells." J Acoust Soc Am 60(2): 510-512.

Dallos, P. and B. N. Evans (1995). "High-frequency motility of outer hair cells and the cochlear amplifier." Science 267(5206): 2006-2009.

Dewey, J. B., B. E. Applegate and J. S. Oghalai (2019). "Amplification and Suppression of Traveling Waves along the Mouse Organ of Corti: Evidence for Spatial Variation in the Longitudinal Coupling of Outer Hair Cell-Generated Forces." J Neurosci 39(10): 1805-1816.

Dong, W. and E. S. Olson (2008). "Supporting evidence for reverse cochlear traveling waves." Acoust Soc Am 123(1): 222-240.

Dong, W. and E. S. Olson (2013). "Detection of cochlear amplification and its activation." Biophys J 105(4): 1067-1078.

Dong, X. X., M. Ospeck and K. H. Iwasa (2002). "Piezoelectric reciprocal relationship of the membrane motor in the cochlear outer hair cell." Biophys J 82(3): 1254-1259.

Dreisbach, L. E. and J. H. Siegel (2001). "Distortion-product otoacoustic emissions measured at high frequencies in humans." J Acoust Soc Am 110(5 Pt 1): 2456-2469.

Fettiplace, R. (2017). "Hair Cell Transduction, Tuning, and Synaptic Transmission in the Mammalian Cochlea." Compr Physiol 7(4): 1197-1227.

Fettiplace, R. and J. H. Nam (2019). "Tonotopy in calcium homeostasis and vulnerability of cochlear hair cells." Hear Res 376: 11-21.

Frank, G., W. Hemmert and A. W. Gummer (1999). "Limiting dynamics of high-frequency electromechanical transduction of outer hair cells." Proc Natl Acad Sci U S A 96(8): 4420-4425. 
Fridberger, A., I. Tomo, M. Ulfendahl and J. Boutet de Monvel (2006). "Imaging hair cell transduction at the speed of sound: dynamic behavior of mammalian stereocilia." Proc Natl Acad Sci U S A 103(6): 1918-1923.

Fritzsch, B., N. Pan, I. Jahan and K. L. Elliott (2015). "Inner ear development: building a spiral ganglion and an organ of Corti out of unspecified ectoderm." Cell Tissue Res 361(1): 7-24.

Frolenkov, G. I., I. A. Belyantseva, M. Kurc, M. A. Mastroianni and B. Kachar (1998). "Cochlear outer hair cell electromotility can provide force for both low and high intensity distortion product otoacoustic emissions." Hear Res 126(1-2): 67-74.

Gale, J. E. and J. F. Ashmore (1994). "Charge displacement induced by rapid stretch in the basolateral membrane of the guinea-pig outer hair cell." Proc Biol Sci 255(1344): 243-249.

Gale, J. E. and J. F. Ashmore (1997). "The outer hair cell motor in membrane patches." Pflugers Arch 434(3): 267-271.

Hallworth, R. (1995). "Passive compliance and active force generation in the guinea pig outer hair cell." J Neurophysiol 74(6): 2319-2328.

He, D. Z. and P. Dallos (1999). "Somatic stiffness of cochlear outer hair cells is voltagedependent." Proc Natl Acad Sci U S A 96(14): 8223-8228.

He, D. Z. and P. Dallos (2000). "Properties of voltage-dependent somatic stiffness of cochlear outer hair cells." J Assoc Res Otolaryngol 1(1): 64-81.

He, D. Z., S. Lovas, Y. Ai, Y. Li and K. W. Beisel (2014). "Prestin at year 14: progress and prospect." Hear Res 311: 25-35.

He, Z. H., R. Bottinelli, M. A. Pellegrino, M. A. Ferenczi and C. Reggiani (2000). "ATP consumption and efficiency of human single muscle fibers with different myosin isoform composition." Biophys J 79(2): 945-961.

Housley, G. D. and J. F. Ashmore (1992). "Ionic currents of outer hair cells isolated from the guinea-pig cochlea." J Physiol 448: 73-98.

Howard, J. and A. J. Hudspeth (1988). "Compliance of the hair bundle associated with gating of mechanoelectrical transduction channels in the bullfrog's saccular hair cell." Neuron 1(3): 189199.

Iwasa, K. H. (1993). "Effect of stress on the membrane capacitance of the auditory outer hair cell." Biophys J 65(1): 492-498.

Iwasa, K. H. (1994). "A membrane motor model for the fast motility of the outer hair cell." J Acoust Soc Am 96(4): 2216-2224. 
Iwasa, K. H. (2016). "Energy Output from a Single Outer Hair Cell." Biophys J 111(11): 25002511.

Iwasa, K. H. and M. Adachi (1997). "Force generation in the outer hair cell of the cochlea." Biophys J 73(1): 546-555.

Jia, S. and D. Z. He (2005). "Motility-associated hair-bundle motion in mammalian outer hair cells." Nat Neurosci 8(8): 1028-1034.

Johnson, S. L., M. Beurg, W. Marcotti and R. Fettiplace (2011). "Prestin-driven cochlear amplification is not limited by the outer hair cell membrane time constant." Neuron 70(6): 1143-1154.

Kakehata, S. and J. Santos-Sacchi (1995). "Membrane tension directly shifts voltage dependence of outer hair cell motility and associated gating charge." Biophys J 68(5): 2190-2197.

Kemp, D. (1998). Otoacoustic emissions: Distorted echoes of the cochlea's traveling wave. Otoacoustic Emissioins: Basic Science and Clinical Applications. C. Berlin. San Diego, Singular Publishing Group: 1-59.

Kemp, D. and A. Brown (1983). An integrated view of cochlear mechanical nonlinearities observable from the ear canal. Mechanics of Hearing. E. de Boer and M. Viergever. The Hague, Martinus Nijhoff: 75-82.

Kennedy, H. J., A. C. Crawford and R. Fettiplace (2005). "Force generation by mammalian hair bundles supports a role in cochlear amplification." Nature 433(7028): 880-883.

Kennedy, H. J., M. G. Evans, A. C. Crawford and R. Fettiplace (2006). "Depolarization of cochlear outer hair cells evokes active hair bundle motion by two mechanisms." J Neurosci 26(10): 27572766.

Koppl, C., V. Wilms, I. J. Russell and H. G. Nothwang (2018). "Evolution of Endolymph Secretion and Endolymphatic Potential Generation in the Vertebrate Inner Ear." Brain Behav Evol 92(1-2): $1-31$.

Lenz, D., J. Hartmann and D. Oliver (2020). Local electrostatics control electromotile conformational transitions of Prestin/SLC26A5. Assoc. Res. Otolaryngol., ARO.

Li, Y., H. Liu, X. Zhao and D. Z. He (2020). "Endolymphatic Potential Measured From Developing and Adult Mouse Inner Ear." Front Cell Neurosci 14: 584928.

Liberman, M. C., J. Gao, D. Z. He, X. Wu, S. Jia and J. Zuo (2002). "Prestin is required for electromotility of the outer hair cell and for the cochlear amplifier." Nature 419(6904): 300-304.

Lonsbury-Martin, B. L. and G. K. Martin (2003). "Otoacoustic emissions." Curr Opin Otolaryngol Head Neck Surg 11(5): 361-366. 
Ludwig, J., D. Oliver, G. Frank, N. Klocker, A. W. Gummer and B. Fakler (2001). "Reciprocal electromechanical properties of rat prestin: the motor molecule from rat outer hair cells." Proc Natl Acad Sci U S A 98(7): 4178-4183.

Lymn, R. W. and E. W. Taylor (1971). "Mechanism of adenosine triphosphate hydrolysis by actomyosin." Biochemistry 10(25): 4617-4624.

Martin, G. K., B. B. Stagner, W. Dong and B. L. Lonsbury-Martin (2020). "An intracochlear DPgram: Proof of principle in noise-damaged rabbits." Hear Res 396: 108058.

Martin, P., D. Bozovic, Y. Choe and A. J. Hudspeth (2003). "Spontaneous oscillation by hair bundles of the bullfrog's sacculus." J Neurosci 23(11): 4533-4548.

Martin, P., A. D. Mehta and A. J. Hudspeth (2000). "Negative hair-bundle stiffness betrays a mechanism for mechanical amplification by the hair cell." Proc Natl Acad Sci U S A 97(22): 12026-12031.

Mercier, P. P., A. C. Lysaght, S. Bandyopadhyay, A. P. Chandrakasan and K. M. Stankovic (2012). "Energy extraction from the biologic battery in the inner ear." Nat Biotechnol 30(12): 12401243.

Morell, M., A. W. Vogl, I. J. LL, M. Piscitelli-Doshkov, L. Tong, S. Ostertag, M. Ferreira, N. FraijaFernandez, K. M. Colegrove, J. L. Puel, S. A. Raverty and R. E. Shadwick (2020). "Echolocating Whales and Bats Express the Motor Protein Prestin in the Inner Ear: A Potential Marker for Hearing Loss." Front Vet Sci 7: 429.

Mountain, D. C. and A. E. Hubbard (1994). "A piezoelectric model of outer hair cell function." Acoust Soc Am 95(1): 350-354.

Muller, M. (1996). "The cochlear place-frequency map of the adult and developing Mongolian gerbil." Hear Res 94(1-2): 148-156.

O Maoiléidigh, D. and A. J. Hudspeth (2013). "Effects of cochlear loading on the motility of active outer hair cells." Proc Natl Acad Sci U S A 110(14): 5474-5479.

O Maoiléidigh, D. and F. Jülicher (2010). "The interplay between active hair bundle motility and electromotility in the cochlea." J Acoust Soc Am 128(3): 1175-1190.

Ospeck, M., X. X. Dong, J. Fang and K. H. Iwasa (2006). "Electromotility in outer hair cells: a supporting role for fast potassium conductance." ORL J Otorhinolaryngol Relat Spec 68(6): 373377.

Ospeck, M., X. X. Dong and K. H. Iwasa (2003). "Limiting frequency of the cochlear amplifier based on electromotility of outer hair cells." Biophys J 84(2 Pt 1): 739-749. 
Patuzzi, R. (2011). "Ion flow in stria vascularis and the production and regulation of cochlear endolymph and the endolymphatic potential." Hear Res 277(1-2): 4-19.

Perez-Flores, M. C., J. H. Lee, S. Park, X. D. Zhang, C. R. Sihn, H. A. Ledford, W. Wang, H. J. Kim, V. Timofeyev, V. Yarov-Yarovoy, N. Chiamvimonvat, R. D. Rabbitt and E. N. Yamoah (2020). "Cooperativity of Kv7.4 channels confers ultrafast electromechanical sensitivity and emergent properties in cochlear outer hair cells." Sci Adv 6(15): eaba1104.

Pujol, R., M. Lenoir, S. Ladrech, F. Tribillac and G. Rebillard (1992). Correlation Between the Length of Outer Hair Cells and the Frequency Coding of the Cochlea. Auditory Physiology and Perception. Y. Cazals, K. Horner and L. Demany, Pergamon: 45-52.

Rabbitt, R. D. (2020). "The cochlear outer hair cell speed paradox." Proc Natl Acad Sci U S A.

Rabbitt, R. D. (2021). "Outer hair cell power output and the cellular origins of distortion products."

Rabbitt, R. D., S. Clifford, K. D. Breneman, B. Farrell and W. E. Brownell (2009). "Power efficiency of outer hair cell somatic electromotility." PLoS Comput Biol 5(7): e1000444.

Racicot, R. A., R. W. Boessenecker, S. A. F. Darroch and J. H. Geisler (2019). "Evidence for convergent evolution of ultrasonic hearing in toothed whales (Cetacea: Odontoceti)." Biol Lett 15(5): 20190083.

Rhode, W. S. and L. Robles (1974). "Evidence from Mossbauer experiments for nonlinear vibration in the cochlea." J Acoust Soc Am 55(3): 588-596.

Santos-Sacchi, J., D. Navaratnam and W. Tan (2020). "State dependent effects on the frequency response of prestin real and imaginary components of nonlinear capacitance." arXiv (arXiv:2012.08088).

Santos-Sacchi, J., W. Shen, J. Zheng and P. Dallos (2001). "Effects of membrane potential and tension on prestin, the outer hair cell lateral membrane motor protein." J Physiol 531(Pt 3): 661-666.

Santos-Sacchi, J. and W. Tan (2018). "The Frequency Response of Outer Hair Cell VoltageDependent Motility Is Limited by Kinetics of Prestin." J Neurosci 38(24): 5495-5506.

Santos-Sacchi, J. and W. Tan (2019). "Voltage Does Not Drive Prestin (SLC26a5) ElectroMechanical Activity at High Frequencies Where Cochlear Amplification Is Best." iScience 22: 392-399.

Santos-Sacchi, J. and W. Tan (2020). "Complex nonlinear capacitance in outer hair cell macropatches: effects of membrane tension." Sci Rep 10(1): 6222. 
Shera, C. A. (2004). "Mechanisms of mammalian otoacoustic emission and their implications for the clinical utility of otoacoustic emissions." Ear Hear 25(2): 86-97.

Shera, C. A. and K. K. Charaziak (2019). "Cochlear Frequency Tuning and Otoacoustic Emissions." Cold Spring Harb Perspect Med 9(2).

Sirovich, L. and B. W. Knight (1977). "On subthreshold solutions of the Hodgkin-Huxley equations." Proc Natl Acad Sci U S A 74(12): 5199-5202.

Szalai, R., K. Tsaneva-Atanasova, M. E. Homer, A. R. Champneys, H. J. Kennedy and N. P. Cooper (2011). "Nonlinear models of development, amplification and compression in the mammalian cochlea." Philos Trans A Math Phys Eng Sci 369(1954): 4183-4204.

Thomas, N., Y. Imafuku and K. Tawada (2001). "Molecular motors: thermodynamics and the random walk." Proc Biol Sci 268(1481): 2113-2122.

Tolomeo, J. A. and C. R. Steele (1995). "Orthotropic piezoelectric properties of the cochlear outer hair cell wall." J Acoust Soc Am 97(5 Pt 1): 3006-3011.

Tolomeo, J. A. and C. R. Steele (1998). "A dynamic model of outer hair cell motility including intracellular and extracellular fluid viscosity." J Acoust Soc Am 103(1): 524-534.

Vavakou, A., N. P. Cooper and M. van der Heijden (2019). "The frequency limit of outer hair cell motility measured in vivo." Elife 8.

Wang, Y., C. R. Steele and S. Puria (2016). "Cochlear Outer-Hair-Cell Power Generation and Viscous Fluid Loss." Sci Rep 6: 19475.

Zdebik, A. A., P. Wangemann and T. J. Jentsch (2009). "Potassium ion movement in the inner ear: insights from genetic disease and mouse models." Physiology (Bethesda) 24: 307-316.

Zheng, J., W. Shen, D. Z. He, K. B. Long, L. D. Madison and P. Dallos (2000). "Prestin is the motor protein of cochlear outer hair cells." Nature 405(6783): 149-155.

Zidanic, M. and W. E. Brownell (1990). "Fine structure of the intracochlear potential field. I. The silent current." Biophys J 57(6): 1253-1268. 


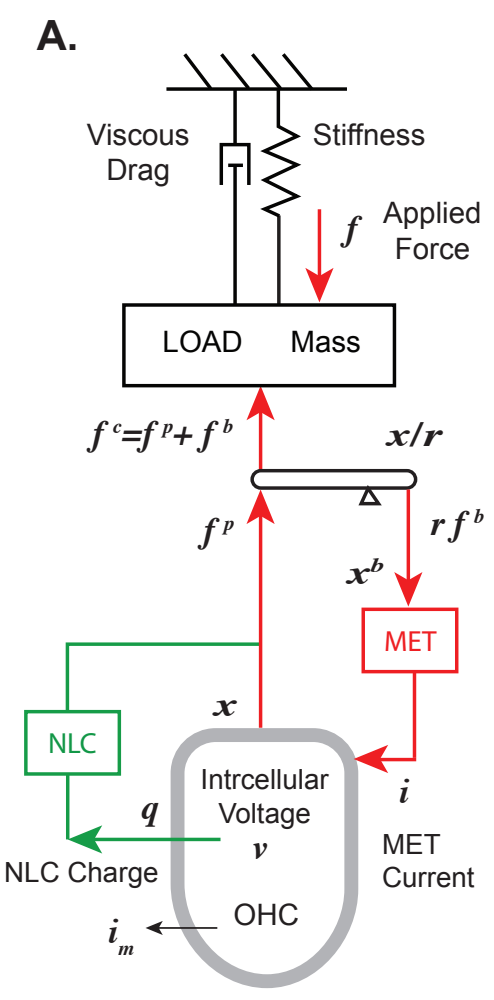

B. MET Step Bundle
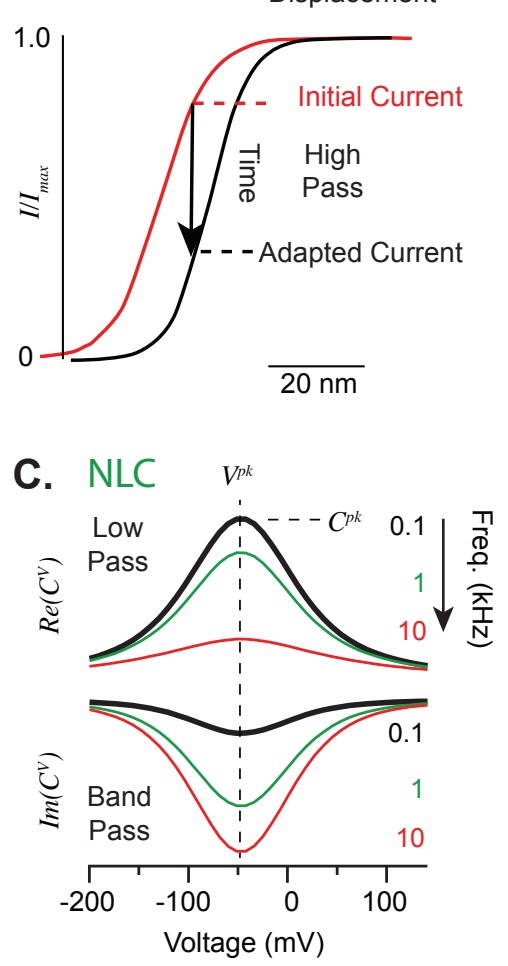
bioRxiv preprint doi: https://doi.org/10.1101/2021.07.29.454372; this version posted July 29, 2021. The copyright holder for this preprint (which was not certified by peer review) is the author/funder. All rights reserved. No reuse allowed without permission.

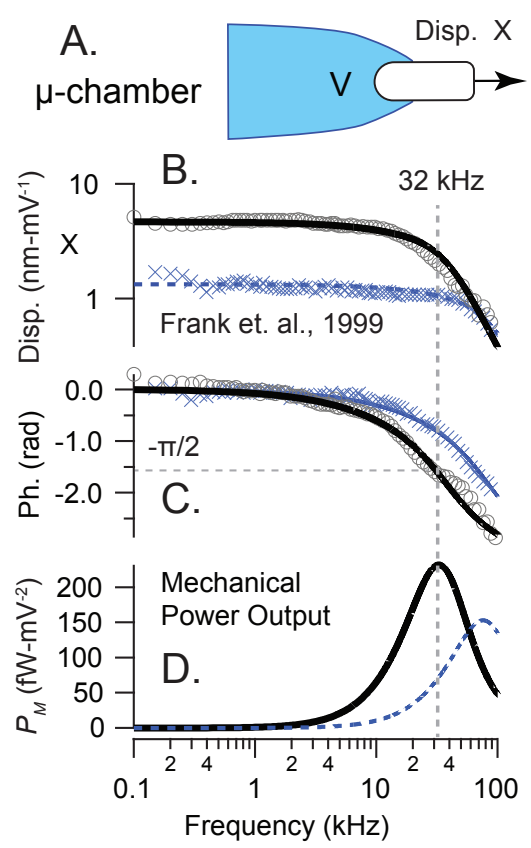


bioRxiv preprint doi: https://doi.org/10.1101/2021.07.29.454372; this version posted July 29, 2021. The copyright holder for this preprint (which was not certified by peer review) is the author/funder. All rights reserved. No reuse allowed without permission.
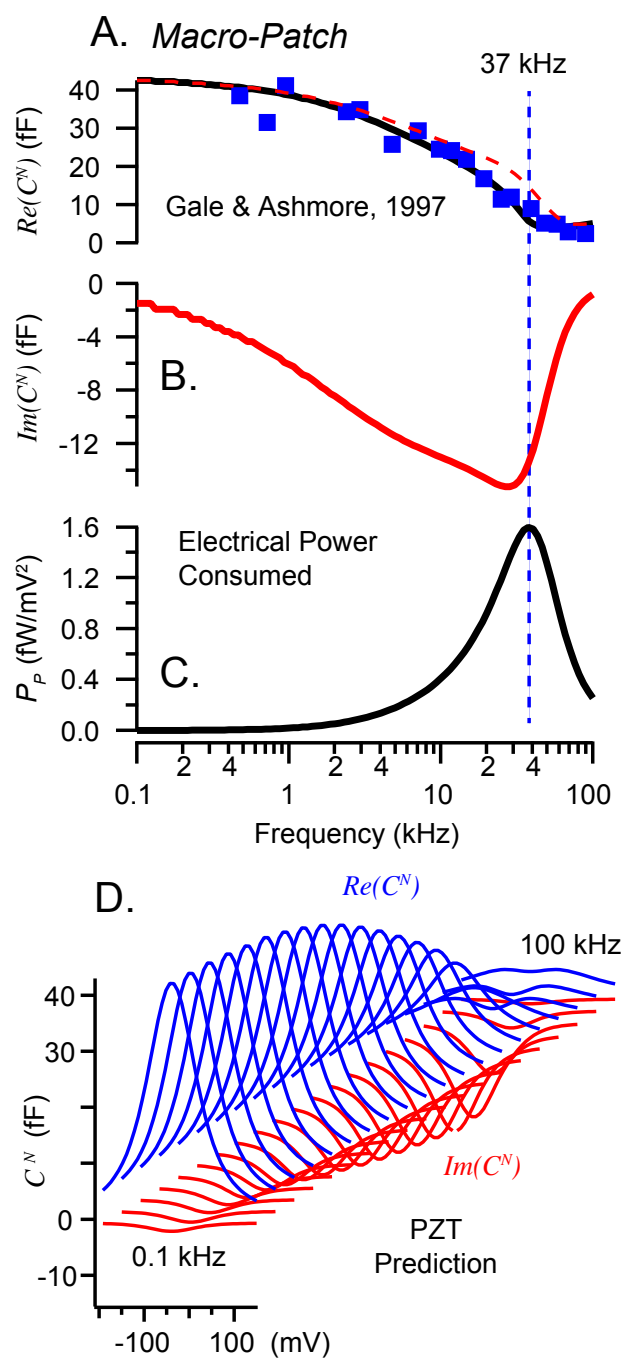

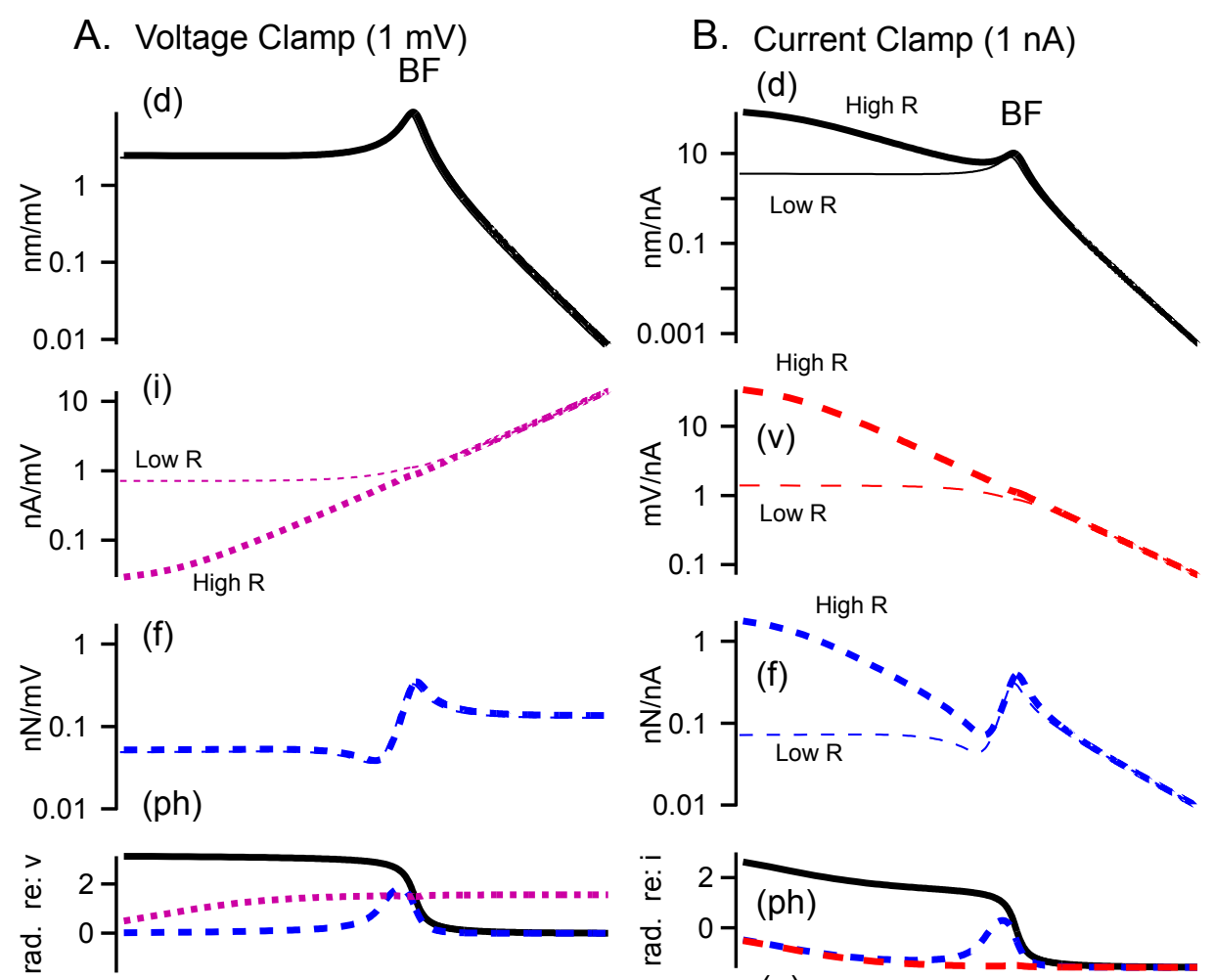

C. Force Clamp $(1 \mathrm{nN})$
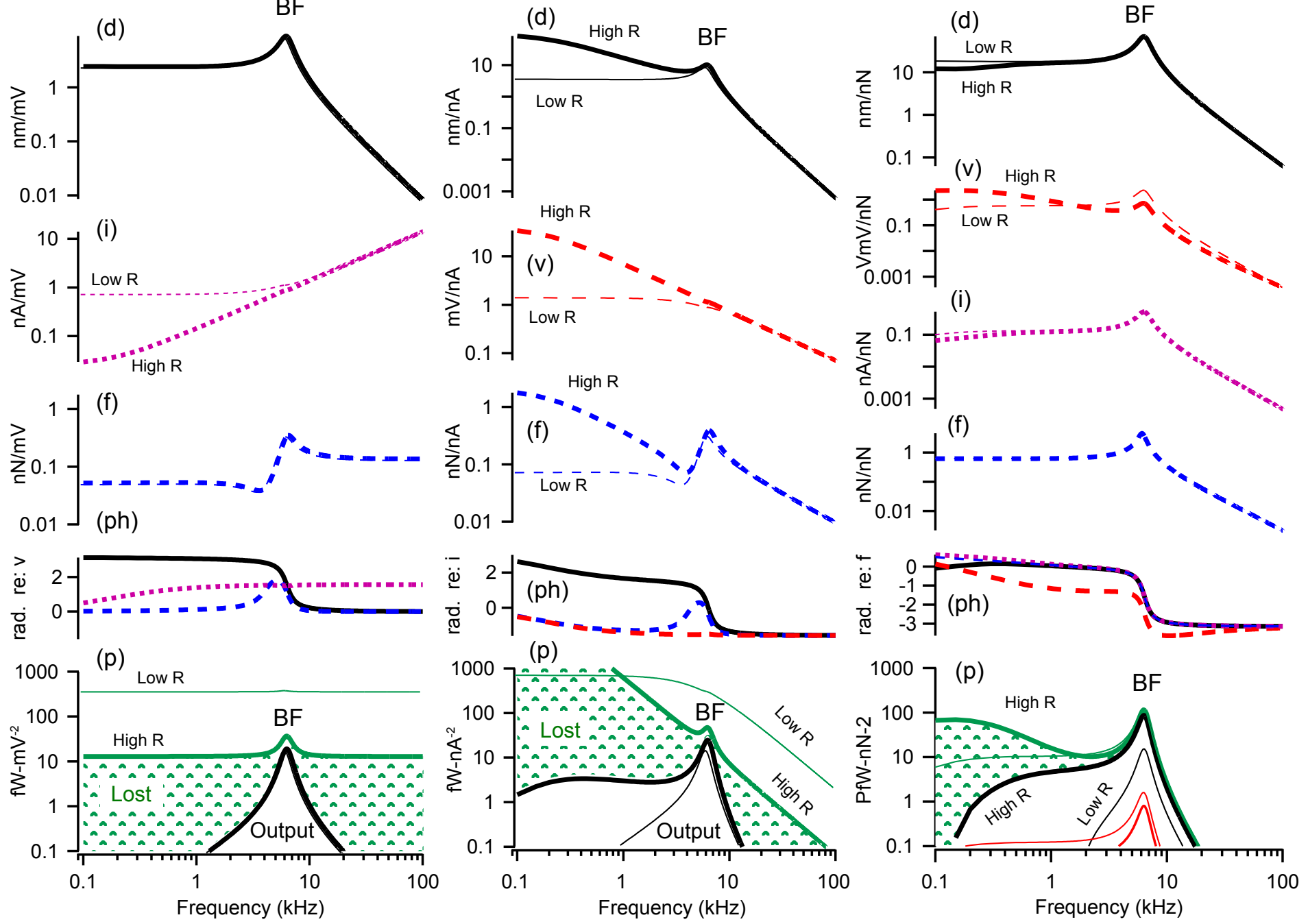
A. VC $25 \mu \mathrm{m}$ OHC. Near BF
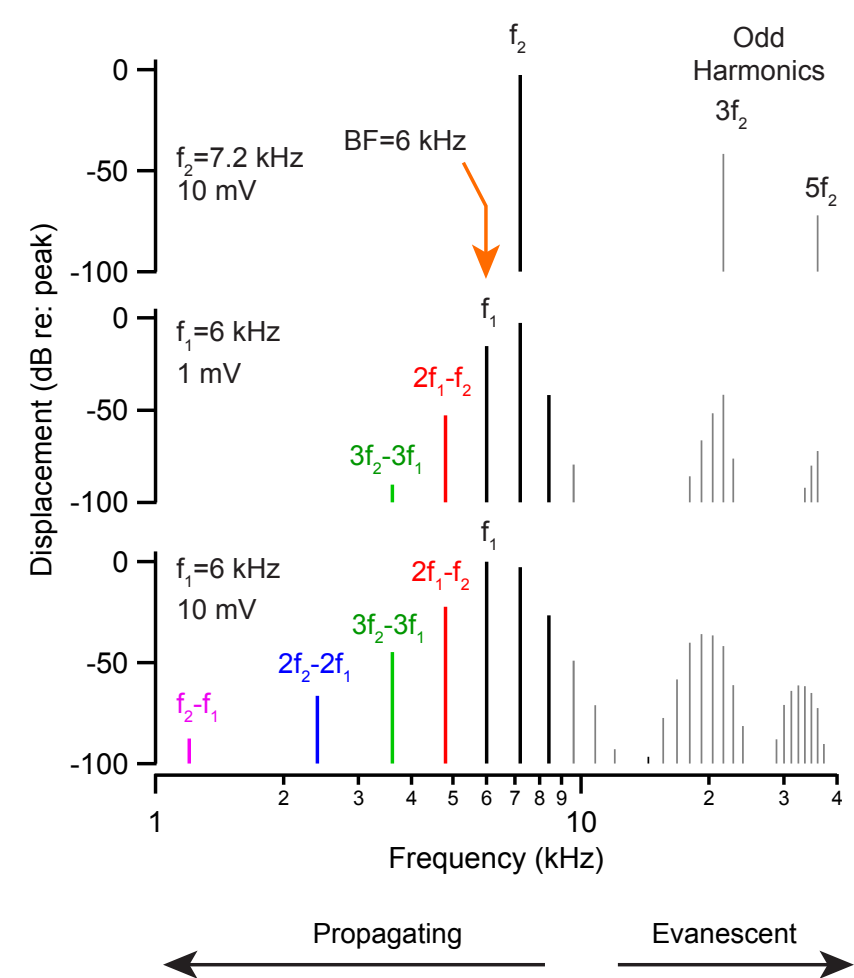

B. FC $25 \mu \mathrm{m} \mathrm{OHC}$. Near BF

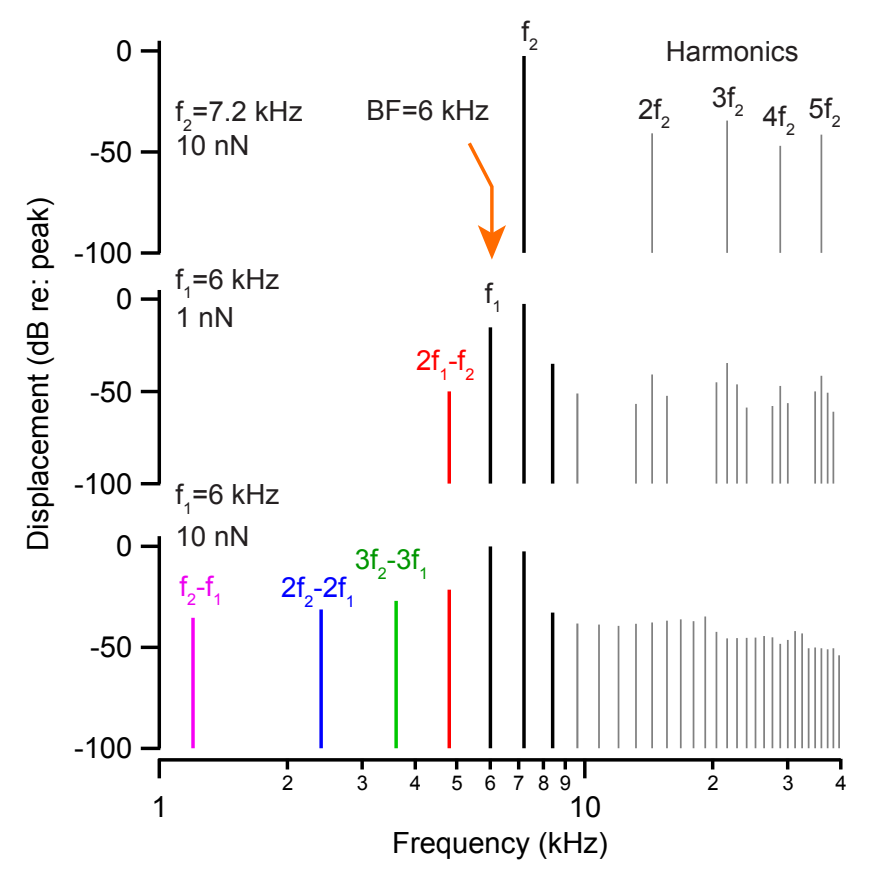




\section{A. VC $25 \mu \mathrm{m}$ OHC. Basal to BF}
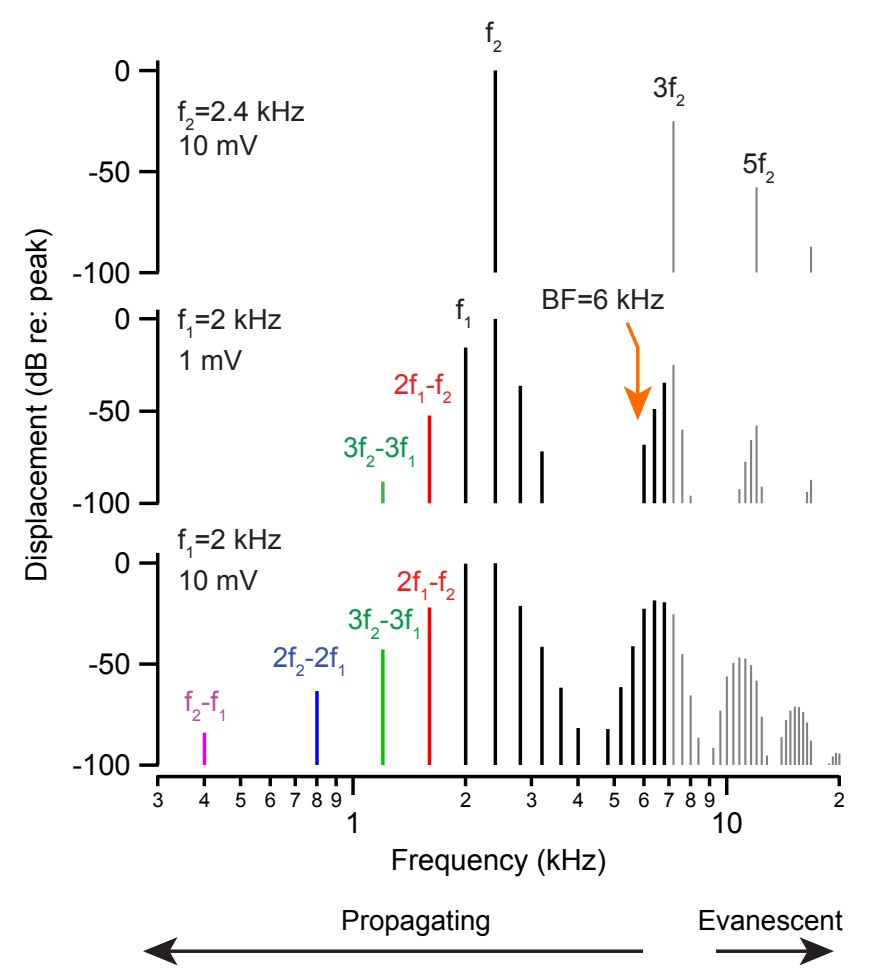

B. FC $25 \mu \mathrm{m} \mathrm{OHC}$. Basal to BF

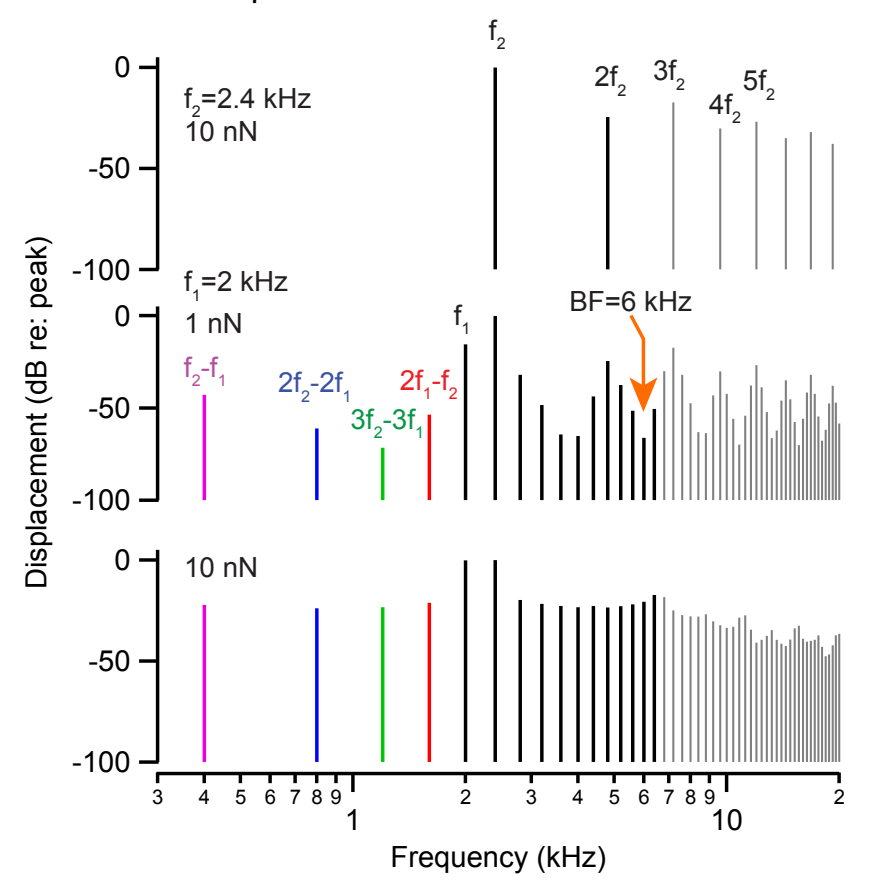

